\title{
Dynamic Responses of Major Pacific Rim Emerging Equity Markets to the US Crude Oil Fear Index (OVX)
}

\author{
Bahram Adrangi ${ }^{1}$ and Arjun Chatrath ${ }^{1}$
}

\begin{abstract}
This study examines the reaction of four major emerging equity markets of the Pacific Rim to the US oil market fear index (i.e., the Chicago Board of Trade Volatility Index, OVX). The OVX is designed to perform as a leading indicator of the volatility in crude oil markets. Our study examines the daily data for the period of 2014 through 2019. We excluded data for the extraordinary and transitory COVID-19 time period. We found that, during this period, there were four significant breaks in the data. Impulse responses from the structural vector autoregressive (SVAR) estimation show that in the second and third subperiods, from December 2016 through December 2018, the volatility of the equity markets of Hong Kong, Shanghai, Seoul, and Taiwan responded to structural shocks to the OVX. Nonlinear Granger causality tests confirmed these findings. This period is characterized by geopolitical crises, like nuclear proliferation on the Korean Peninsula and lingering complications surrounding the Brexit referendum.
\end{abstract}

JEL classification numbers: G10, G15, G17

Keywords: volatility, Pacific Rim Equity Markets, OVX, structural vector autoregression, GARCH Models, causality

\section{Introduction}

This study examines the responses of four major emerging market equity markets in the Pacific Rim to the Chicago Board of Exchange (CBOE) Crude Oil ETF Volatility Index ("Oil VIX" or OVX). The OVX functions similar to the VIX. The OVX measures the market's expectation of the thirty-day implied volatility of crude oil prices by applying the VIX methodology to the United States Oil Fund LP (Ticker: USO) options covering a wide range of strike prices. VIX is the first implied volatility index by CBOE and the precursor of other similar indices in the US and around the world. OVX is normally positively correlated with crude oil prices. The higher values of the OVX are usually associated with rising crude oil prices. The information content of the OVX may be another tool to predict crude oil prices and the subsequent ramifications of its movement for financial markets. For instance, upward movements of OVX may be positive for bond markets and currency values in exporting economies and negative for the equity prices in most economies. Thus, tracking the movements of the OVX may offer hedge strategies for investors as well as corporations.

The VIX method and, by extension, OVX methodology aggregates Black Scholes implied volatility over various strike prices using a particular expiry (thirty days). The volatility smile patterns are aggregated so that changes to extreme implied volatility are dampened. The OVX is designed in a similar manner to the VIX. Like VIX, the OVX is calculated by interpolating two weighted sums of the option mid-quote

\footnotetext{
${ }^{1}$ University of Portland, USA
}

Article Info: Received: November 9, 2021. Revised: January 1, 2022. Published online: January 12, 2022 
values and, in this case, options on the OVX ETF. High readings of the OVX may indicate a downside risk for the crude oil price in the next 30 days. The OVX, like VIX, may suffer from some of the same problems that other leading indicators do. For instance, practitioners note that there have been periods when VIX predictions and market movements have diverged inconsistently based on predictions for VIX, such as the four months between August 8, 2017, and November 8, 2017, when VIX was up 19\%, signaling rising fear among market participants. This would imply a downward trend in the S\&P 500.

It may be informative to investigate the relationship between OVX and future volatility in the equity markets of the world. Indeed, there are many studies that have examined similar cross-market relationships between VIX and equity markets.

This study examines the reactions of the equity indices of Hong Kong, Korea, Shanghai, and Taiwan to the OVX. The importance of these economies and their equity markets cannot be underestimated. In 1950, these economies were among the world's least developed countries. Today, driven by their free market economic policies and vibrant capital markets, Hong Kong, South Korea, and Taiwan are known as the Asian tigers. China is the world's second largest economy.

The objective is to determine whether investors in these markets are sensitive to movements in crude oil prices and, by association, to the OVX. While China is the fourth largest crude oil producer in the world, the remaining three indices represent the equity indices of economies that are dependent on imported crude oil. If it is found that the OVX performs as a leading indicator of equity market movements, this may provide useful information for the valuation of implied volatility-based derivatives, hedging strategies based on OVX fluctuations, and option pricing, among other financial strategies. Furthermore, practitioners view the OVX and similar fear indices, such as VIX, as a predictor of market movements in the near future. This is the main reason why the OVX was created by the CBOE as a leading indicator, and findings from the present study may confirm or contradict this notion.

Our study formally tests for structural breaks in the OVX for the period of the study. We identify four distinct subperiods and estimate a structural vector autoregressive model (SVAR) for each one. In each subperiod we test the response of equity markets and their volatility to structural shocks to the OVX. Detecting nonlinearities in the time series under consideration, we deploy the nonlinear Granger causality test (see Skalin and Svirta, 1999) to examine the robustness of our findings in regard to the predictive power of the OVX as a leading indicator of market movement. These findings may collectively have implications for hedging strategies, particularly if the findings suggest a disparate reaction to the OVX movement in these major emerging equity markets.

The remainder of the paper is organized as follows: Section II offers a brief review of the relevant literature, data are explained in Section III, the methodology of the research is the subject of Section IV, and Section V consists of the analysis of the empirical findings. The last section is devoted to a summary and conclusions.

\section{Review of the Relevant Literature}

Many researchers have investigated the association of volatility in crude oil prices with crude oil distillates, equity markets, and exchange rates, among other factors. Kilian and Park (2009) investigated the role of oil price shocks in the volatility of US equity markets. Adrangi et al. (2001) analyzed the price dynamics of Alaska North Slope crude oil and L.A. diesel fuel prices by estimating vector autoregressive (VAR) and bivariate GARCH models to show that there is strong evidence of a unidirectional causal relationship between the two prices.

In another study, Adrangi et al. (2018) examined the monthly movements of US diesel prices for the period 1974-2017. The SVAR formulation and the vector error correction models (VECMs) suggest that global demand shocks to crude oil, including the inventory of crude oil in the US, are primarily responsible for diesel price movements in the US, accounting for up to 30-70\% of its variation.

Adrangi et al. (2015) studied the daily volatility spillovers between crude oil prices and equity indices for a group of major equity markets. Bivariate generalized autoregressive conditional heteroscedasticity 
(VAR-GARCH) estimations indicate bidirectional volatility spillovers. After finding evidence of asymmetric market responses to negative and positive shocks, they estimated asymmetric bivariate VARexponential GARCH (VAR-EGARCH) models. Their findings confirmed the shock transmissions to be asymmetric, and the positive and negative shocks of the same size on oil prices have an unequal influence on the volatility of equities.

Adrangi et al. (2020) examined the impact of crude oil price fluctuations on equity markets for four emerging Latin American markets: Argentina, Brazil, Chile, and Mexico. Their study investigates this association in time and frequency domains. The co-spectral analysis confirms that most of the observable coherence between crude oil and equity returns occurred at relatively short frequencies. The SVAR results suggest that shocks to crude oil prices lead all equity markets into negative territory, though they typically reversed course after approximately twenty-four months. The nonlinear Granger causality tests reveal that, with the exception of the Merval Index, the equity markets under study were responsive to crude oil price shocks.

Lundberg et al. (2020) found that energy represents an important share of production costs for many agricultural commodities. They used a new wavelet-based regression approach to explore horizon-based heterogeneity in the relationship between oil and agricultural commodity prices. They present evidence of heterogeneity across time horizons and commodities. Lundberg et al. (2020) show that agricultural contracts can generate price stickiness that leads to heterogeneity in crude oil cost pass-through over different horizons.

The focus of previous studies has been on crude oil prices and their volatility. Since 2007, OVX has emerged as an indicator of volatility in crude oil prices. The information content of the OVX may be a reliable tool to predict crude oil prices and the subsequent ramifications of its movements for financial markets. Furthermore, because of its leading indicator role, tracking the movements of the OVX, similar to those of the VIX, may offer hedging strategies for equity and commodity markets.

The association of the OVX with equities, particularly equities of emerging economies, has not been explored in the literature. Researchers have investigated the role of OVX in other contexts. For instance, Wen et al. (2019) investigated the association of macroeconomic variables in China with the US economic policy uncertainty index (EPU), the VIX, and the OVX. Chen et al. (2015) employed Kalman filter regressions to study the dynamic relationship between the OVX and future crude oil prices. Lin and Tsai (2019) studied the daily data for Brent crude oil prices and the VIX and OVX indices. The closest to the present research is Ahmad et al. (2018), who examined VIX, OVX, and other commodities as hedging tools to hedge investments in clean energy equities. Our paper fills a gap in the literature by examining a potentially critical role that OVX may have in the equity markets of the major Pacific Rim crude oilimport major economies and their equity markets.

Studies that investigate the role of VIX in the market abound. For instance, several papers in the last decade have researched the association between VIX and other asset classes. Notable among them are papers that investigate fixed-income securities, commodities, and foreign currencies, among other asset categories (see Giot, 2005; Badshah et al., 2013; Boscaljan and Clark, 2013; Jubinski and Lipton, 2013; Sari, 2011; and Adrangi et al., 2019). Studies by Sharma et al. (2019), Ji et al. (2019), Gürsoy (2020), and Cheuathonghua (2019), among others, extend this investigation to cross-market associations of VIX and the equity markets of Europe, BRICS countries, Latin America, and other emerging markets.

While many papers have examined VIX and its information content, predictive power, and time series properties, research on OVX has been limited. Ahmad et al. (2018) examined VIX, OVX, and other commodities as hedging tools to hedge investments in clean energy equities. Their findings - using several different approaches - indicated that VIX may be the most reliable hedging asset for clean energy equities, followed by oil and OVX.

Chen et al. (2015) employed Kalman filter regressions to study the dynamic relationship between OVX and future crude oil prices. Their empirical findings show a negative association between OVX changes and future crude oil price returns except in cases of abnormally high readings of the OVX. Additionally, they further confirm that OVX is a fairly good predictor of the future realized volatility in crude oil price changes. 
Lin and Tsai (2019) studied the daily data for Brent crude oil prices and the VIX and OVX indices from May 10, 2007, to November 13, 2017. They found six structural breaks in the data during their sample time period and the cointegration between the oil price and VIX throughout the sampling period. However, the cointegration between OVX and the Brent crude oil price is not consistent across structural breaks. According to Lin and Tsai (2019), the cointegration relation coupled with correlation analysis indicates that OVX seemed to be better than VIX in predicting oil price changes.

Wen et al. (2019) investigated the association of macroeconomic variables in China with the US economic policy uncertainty index (EPU), VIX, and OVX in a nonlinear cointegrating autoregressive distributed lag (NARDL) framework. Their empirical findings indicated that, with the exception of OVX, there is evidence of a short-run relationship between the measures of uncertainty shocks and China's macroeconomy. In the long run, VIX seems to be the most relevant in fueling uncertainty in China's macroeconomy. However, OVX and EPU also influence economic uncertainty and trigger responses in the inflation rate, output, and money supply, among other indicators. They concluded that policy makers and investors would benefit from tracking the uncertainty indicators in their study.

Qadan et al. (2020) deployed threshold-GARCH, structural vector auto regression, and causality models to investigate the association of risk appetite, oil price returns, and volatility. According to one finding, oil prices and their volatility in recent years are mainly driven by shocks originating in the economic uncertainty and risk appetite of investors in the equity markets and may not depend on structural economic shocks to oil supply and demand. Furthermore, investors' risk tolerance drives changes to OVX, which measures perceptions about future oil volatility. Their findings provide a better understanding of the relationships among oil markets, VIX, and OVX. Most important, they found that variations in the investor's appetite for risk determined equity price variations as well as OVX and crude oil prices.

Kang et al. (2021) employed time-frequency analysis to examine the association among US sector equity ETFs, oil, gold, stock market, and uncertainty factors in the short and long terms. According to Kang et al. (2021), VIX has the strongest effect on US sector equity ETFs in both the short and long runs, and this is followed by OVX. The US EPU has the smallest influence on sector ETFs, and sector ETFs show a stronger association with oil than gold. Co-movements among the sector ETFs, gold, oil, and uncertainty factors exhibit temporal asymmetry and are more pronounced in the short run. Financial and economic uncertainties also intensify the association among them.

Geng et al. (2021) applied graph theory to investigate the information flow among US equities, strategic commodities (oil and gold), and equities in Brazil, Russia, India, China, and South Africa. However, unlike the prior literature, they apply a graph theory approach that incorporates a model to disclose the dynamics of information integration and to investigate the impact of political, military, macroeconomic, and financial events on the changes in information flow among implied volatility indices. Their findings show that the information transmission network is unstable and exhibits temporal dynamics. Their dynamic conditional correlation reveals that some events impact the local market only, whereas others have a global impact.

This paper contributes to the literature by examining the role of OVX in four emerging Pacific Rim equity markets. Specifically, we examine the reaction of the equity markets in major Pacific Rim economies to the fluctuations in OVX. Additionally, we looked for causality between OVX and the equity indices under study. If there is evidence that Pacific Rim equity markets are sensitive to OVX, there may be steps that the investors, wealth management firms, and economic policy makers can take to minimize risks to the economies and financial markets.

\section{Data}

The daily data for the study is for the period that covers September 18, 2014, through September 27, 2019. This period is in the pre-COVID-19 era. Although COVID-19 has been the focus of much attention since early 2020 because of its disruptive effect on all aspects of the world economy, its effects on all industries - and the US economy in particular - is expected to be transitory. The literature shows that the 
impact of economic shocks is often short-lived (see Adrangi et al., 2019). This finding is supported by current observations in the US economy. Most industries are well on their way to returning to their preCOVID-19 levels. For instance, Bloomberg (2021) reports that high-frequency indicators across most measures show that economic growth is returning as the economy reopens from winter lockdowns. Moody's (2020) expects that, with vaccinations on the rise and an ease in government lockdowns, world economies will recover from the pandemic by 2023. According to Forbes (2021), the construction industry has already bounced back to its pre-pandemic level of activity.

The daily index values of the Hang Seng Index (HS) for Hong Kong (HK), the Korea Composite Index (KO), the Shanghai Stock Exchange Index (SH), the Taiwan Stock Exchange Index (TW), and the OVX are taken from the Bloomberg database. These indices represent the main national stock exchanges of the markets under study.

The HS is the main indicator of overall market movements in HK. It is a free-float-adjusted marketcapitalization-weighted stock market index based on fifty companies. These companies represent roughly $59 \%$ of the market capitalization on the Hong Kong Stock Exchange. The HS began on November 24, 1969, and is currently compiled and maintained by Hang Seng Indexes Company Limited, which is a wholly owned subsidiary of Hang Seng Bank, one of the largest market capitalization banks in Hong Kong. The Hongkong and Shanghai Banking Corporation (HSBC) is a multinational British investment bank and is the majority shareholder of Hang Seng Bank.

The KO is the index of all common stocks traded on the Stock Market Division of the Korea Exchange. The KO was introduced in 1983 with a base value of 100 as of January 4, 1980. It is the representative stock market index of South Korea. The KO is calculated based on a market capitalization of over 760 companies. Samsung, Hyundai Motors, and LG are among the highest market capitalization shares included in the index. It is similar to the S\&P 500 in terms of its breadth.

The SH (or SSE Composite Index or SSE Index) is a stock market index of all stocks (A shares and B shares) that are traded on the Shanghai Stock Exchange. ${ }^{[2]}$ The SSE Index debuted in July 1991 and is a Paasche-weighted composite price index. The index is the ratio of the current market capitalization of all A and B stocks divided by the market capitalization on the base day (i.e., December 19, 1990).

The TAIEX is the Taiwan Stock Exchange Corporation Index. The Taiwan Stock Exchange Corporation was created in 1961 and has been a stock exchange since February 1962. There were 809 companies originally listed on the exchange. In December 2019, its market capitalization was approximately 37 million Taiwan dollars. It is regulated by the Taiwan Financial Supervisory Commission.

\section{Methodology}

\section{Structural Vector Autoregressive Formulation}

The main tool for the empirical investigation in this study is a structural vector autoregression model (SVAR). The methodology is well-developed in the literature. Following Adrangi et al. (2019), we offer a brief discussion of the methodology. A SVAR may be written as:

$\mathbf{A} \mathbf{X}_{\mathbf{t}}=\mathbf{B}_{0}+\sum_{i=1}^{s} \mathbf{B}_{\mathbf{i}} \mathbf{X}_{\mathbf{t}-\mathbf{i}}+\mathbf{u}_{\mathbf{t}}$

where $\mathbf{A}$ is a n $\mathrm{x}$ n square matrix and in our case, $5 \mathrm{X} 5$ because we have five endogenous variables, 


$$
\mathbf{A}=\left(\begin{array}{ccccc}
1 & a_{12} & a_{13} & a_{14} & a_{15} \\
a_{21} & 1 & a_{23} & a_{24} & a_{25} \\
a_{31} & a_{32} & 1 & a_{34} & a_{25} \\
a_{41} & a_{42} & a_{43} & 1 & a_{45} \\
a_{51} & a_{52} & a_{53} & a_{54} & 1
\end{array}\right), \mathbf{u}_{\mathrm{t}=}\left(\mathrm{u}_{\mathrm{t}}^{\mathrm{OVx}}, \mathrm{u}_{\mathrm{t}}^{\mathrm{HS}}, \mathrm{u}_{\mathrm{t}}^{\mathrm{KO}}, \mathrm{u}_{\mathrm{t}}^{\mathrm{SH}}, \mathrm{u}_{\mathrm{t}}^{\mathrm{TW}}\right)^{\prime}
$$

where matrix $\mathbf{A}$ is a five-dimensional square matrix of the structural model coefficients, vector $\mathbf{u}_{\mathbf{t}}$ comprises structural shocks, and $\mathbf{X}_{\mathrm{t}}=\left(\mathrm{OVX}_{\mathrm{t}}, \mathrm{HS}_{\mathrm{t}}, \mathrm{KO}_{\mathrm{t}}, \mathrm{SH}_{\mathrm{t}}, \mathrm{TW}_{\mathrm{t}}\right)^{\prime}$ is the vector of model variables. As we will see shortly, except for OVX, the remaining series in vector $\mathrm{x}$ are stationary conditional variances in each market, which are derived from a GARCH $(1,1)$ model. These variables represent market volatility.

The off-diagonal elements of matrix A represent the contemporaneous relationship among the five-by-one $(5 \times 1)$ elements of the vector of the model's stationary endogenous variables (i.e., OVX and time-varying volatility in the five indices). Additionally, $\mathbf{B}_{0}$ is a $5_{X} 1$ vector of intercepts, and $\mathbf{B}_{\mathrm{i}}$ is a $5_{X} 5 \mathrm{X}$ s coefficient matrix of lagged endogenous variables on the right-hand side of Equation (1). There are $5_{\mathrm{X}} 5_{\mathrm{X}} \mathrm{s}$ ( $\mathrm{s}$ is the lag order) parameters to be estimated in matrix $\mathbf{B}_{\mathrm{i}}$. The vector of white noise structural innovations (shocks) is the $5_{\mathrm{X}} 1$ vector $\mathbf{u}_{\mathrm{t}}$ with elements that are uncorrelated with the model's endogenous variables and across equations.

The reduced form of Equation (1) is obtained by multiplying both sides of the equation by the matrix $\mathbf{A}^{-1}$ given by Equation (2),

$\mathbf{X}_{\mathbf{t}}=\mathbf{G}_{0}+\sum_{i=1}^{s} \mathbf{G}_{\mathbf{i}} \mathbf{X}_{\mathbf{t}-\mathbf{i}}+\mathbf{e}_{\mathbf{t}}$

where $\mathbf{G}_{0}=\mathbf{A}^{-1} * \mathbf{B}_{0}, \mathbf{G i}=\mathbf{A}^{-1} * \mathbf{B}$, and $\mathbf{e}_{\mathrm{t}}=\mathbf{A}^{-1} * \mathbf{u}_{\mathrm{t}}$. The elements of vector $\mathbf{e}_{\mathrm{t}}$ (i.e., forecast errors) are a linear function of the structural innovations given by vector $\mathbf{u}_{t}$.

As in most simultaneous systems of equations, initially the reduced-form SVAR is estimated, and the structural parameters are subsequently recovered using these estimates. Having estimates of the structural model allows us to examine the responses of the model variables to the structural shocks of each variable. Equation (3) shows that the structural shocks are a linear combination of the reduced-form forecast errors.

$$
\left[\begin{array}{l}
u_{t}^{O V X} \\
u_{t}^{H S} \\
u_{t}^{K O} \\
u_{t}^{S H} \\
u_{t}^{T W}
\end{array}\right]=\left(\begin{array}{ccccc}
1 & a_{12} & a_{13} & a_{14} & a_{15} \\
a_{21} & 1 & a_{23} & a_{24} & a_{25} \\
a_{31} & a_{32} & 1 & a_{34} & a_{25} \\
a_{41} & a_{42} & a_{43} & 1 & a_{45} \\
a_{51} & a_{52} & a_{53} & a_{54} & 1
\end{array}\right) *\left[\begin{array}{l}
e_{t}^{O V X} \\
e_{t}^{H S} \\
e_{t}^{K O} \\
e_{t}^{S H} \\
e_{t}^{T W}
\end{array}\right]
$$

In Equation (3) the elements of vector $\mathbf{e}_{\mathrm{t}}$ are the forecast errors associated with OVX and the time-varying volatility in the $\mathrm{HS}, \mathrm{KO}, \mathrm{SH}$, and TW equity indices, respectively.

The identification problem in the SVAR models arises because the number of estimated coefficients derived from the reduced form estimation are insufficient to recover the coefficients of the structural 
model and structural shocks. Therefore, some restrictions on the off-diagonal elements of matrix $\mathbf{A}$ in Equation (1) are necessary.

For instance, given the five endogenous variables, we would need to impose ten necessary restrictions (i.e., $\left[n^{2}-n\right] / 2$ ) on the elements of matrix $\mathbf{A}$, where $n=5$. These restrictions are sufficient to render the remaining unrestricted elements $\mathrm{a}_{\mathrm{i}}$ of matrix $\mathbf{A}$ in Equation (3) identifiable.

The SVAR estimations are often used to analyze impulse responses and prediction error innovation accounting (i.e., variance decomposition). To obtain the impulse responses and to perform the innovation accounting, the estimates of the reduced-form coefficients and the covariance matrix of the forecast errors in the reduced form are needed to obtain the structural model coefficients and innovations. Using an identification strategy, the structural shocks in Equation (1) (i.e., the elements of vector $\mathbf{u}_{t}$ ) are fully recoverable from the forecast errors in the reduced-form model by Equation (2).

We impose a long-run restriction assuming that cumulative impulse responses of equity markets to the shocks to OVX shocks are negligible (Blanchard, 1989; Blanchard and Quah, 1989). This assumption is plausible because, while the shocks to OVX may trigger volatility in equity markets, in the long run the economic fundamentals and firm cash flows determine the direction of equities and indices. The reducedform forecast errors are a function of structural errors, such as:

$$
\boldsymbol{\Psi} \mathbf{e}_{\mathbf{t}}=\mathbf{F} \mathbf{u}_{t}
$$

where matrix $\boldsymbol{\Psi}$ is an inverse matrix with long-run multipliers as its elements. From this equation, the reduced-form errors and their covariance matrix may be computed as $\mathbf{e}_{\mathbf{t}}=\boldsymbol{\Psi}^{-1} \mathbf{F} \mathbf{u}_{t}$ and $\mathbf{E}\left(\mathbf{e}_{\mathbf{t}} \mathbf{e}_{\mathbf{t}}^{\prime}\right)=\boldsymbol{\Sigma}_{\mathbf{e}}$, where $\boldsymbol{\Sigma}_{\mathbf{e}}=\boldsymbol{\Psi}^{-1} \mathbf{F F} \boldsymbol{\Psi}^{-1}$. The long-run identifying restrictions are imposed by setting elements of matrix F equal to zero. For instance, $F_{i j}=0$ implies that the long-run accumulated impulse response of variable I to shocks to the variable $\mathrm{j}$ is zero.

Finally, the Wold representation of the estimated structural model in Equation (1) is written in an infinite moving average representation of the structural shocks as follows:

$$
\mathbf{X}_{t}=\mathbf{\Omega}+\sum_{j=0}^{\infty} \boldsymbol{\Phi}_{i} \mathbf{u}_{t-j}
$$

where $\boldsymbol{\Omega}$ and $\Phi$ are the vector of intercepts and the matrix of infinite structural shocks, respectively.

As discussed by Adrangi et al. (2019), elements of matrix $\Phi$ in Equation (4) can be used to derive variable responses to structural shocks to other model variables. For instance, $\phi_{\mathrm{ij}}(0)$ is the instantaneous impact of a shock to innovation $j$ on the endogenous variable $i$ and is called the impact multiplier. Oneperiod impacts of shocks to innovation $\mathrm{j}$ on variable $\mathrm{i}$ in time period $\mathrm{t}$ are given by $\phi_{\mathrm{ij}}(\mathrm{t})$. Furthermore, by performing innovation accounting, one can examine the forecast error variance or variance decomposition. If shocks to a structural innovation explain none of the forecast error variance of the endogenous variable $\mathrm{x}_{\mathrm{j}}$, then the series $\mathrm{x}_{\mathrm{j}}$ is unrelated to the remaining endogenous variables of the model. Imposing long-run restrictions requires that the variables in the estimated SVAR are stationary. Table 1 shows that in most subperiods the equity market indices under study are not stationary. Furthermore, the objective of the research is to examine the association of volatility in each market with OVX. Therefore, prior to estimating SVAR, we derive the time-varying volatility in each index by fitting GARCH (11) models to each index return. The mean equation of returns for each index is given by Equation (5) as: 
$R_{t}=\sum_{i=1}^{p} \pi_{i} R_{t-i}+\varepsilon_{t}$

where $R_{t}$ represents the percentage changes in each series. The lag length for each series is selected based on the Akaike (1974) criterion. The residual term $\left(\varepsilon_{t}\right)$ represents the index movements that are purged of linear relationships and seasonal influences. The conditional variance equation of index returns in the GARCH $(1,1)$ model is given by Equation (6) as:

$\sigma_{i, t}^{2}=\beta_{i}+\gamma_{i} u_{i, t-1}^{2}+\varphi_{i} \sigma_{i, t-1}^{2} \mathrm{i}=1$ to 4,

where $\sigma_{i, t}^{2}$ is the conditional variance, $\mathrm{u}_{\mathrm{i}, \mathrm{t}-1}$ is the lagged innovations, and $\sigma_{\mathrm{i}, \mathrm{t}-\mathrm{i}}^{2}$ is the lagged conditional volatility. The GARCH models are estimated by the maximum likelihood method.

\section{Empirical Results}

Before estimating the SVAR and examining the impulse responses, we plot the daily graphs of every time series under study.

A visual inspection of the time series plot of the equity indices shows clear evidence that the indices are not stationary. These graphs are not provided for the purpose of brevity. Figure 1 reveals that, while OVX may be stationary during certain subsets of the period under study, structural breaks are also visible. The focus of the study is on the shocks to OVX and their impact on the equity indices under study. Therefore, we use the breaks in OVX to determine the subperiod in which we examine the impulse responses.

Structural breaks in the OVX series might have been related to several geopolitical events during the time period of the study. Structural shifts in the crude oil markets, Brexit, and China-US trade and tariff disputes are some of the geopolitical events that could be responsible for structural breaks in OVX. We briefly discuss these events and their potential impact on the crude oil market.

The advent of technological improvements, such as hydraulic fracturing as well as the reserves of shale oil, have altered the global oil market and placed the US as the number one oil-producing country. These events have reduced the market power of OPEC, and the result was a precipitous drop in crude oil prices to around \$29 per barrel by January 2016. Prices have recovered to some degree as a result of efforts by OPEC and the world's third largest crude oil producer, Russia.

The election of US President Donald Trump ushered in a new era for international cooperation and trade. Even on the campaign trail, candidate Trump criticized many international accords signed by previous administrations, including the Trans-Pacific Partnership (TPP), which added to geopolitical uncertainty and threatened trade between the US and other members and indirectly among the Pacific Rim economies. Ultimately, the US withdrew from the TPP in January 2017.

The emergence of the US as a major crude oil producer has significantly reduced the power of other crude oil suppliers, such as OPEC and Russia, and affects the supply side and controls crude oil prices. However, geopolitical uncertainties in the Middle East and the trade dispute between China and the US may be factors behind the volatility of crude oil prices. The uncertainty stemming from some of the economic and geopolitical events has contributed to firm crude oil prices around $\$ 75$ per barrel. Furthermore, the weakening global economy may have reduced demand for crude oil and caused downward pressure on crude oil prices. The upshot of these uncertainties is that OVX has experienced several structural break points.

Brexit and the trade dispute between the two largest economies of the world have threatened world economic growth. A slowdown of global economic growth would add to uncertainties on the demand side of the crude oil market. Examining the OVX graph shows that OVX is emitting mixed signals during the 
period of study. The structural breaks in OVX likely reflect the contradictory consequences of the underlying supply and demand conditions as well as uncertainties stemming from geopolitical developments.

Table 1 reports the results of a Bai-Perron test of structural breaks in the OVX. The test signals three structural breaks that occurred on November 11, 2016; December 28, 2017; and November 30, 2018; constituting four subperiods. Thus, we estimate four SVARs, one for each subperiod, and extract the impulse responses of the four equity indices to the shocks to the OVX.

The SVAR model coefficients are based on estimating an unrestricted VAR for the stationary time series. Some variables of the SVAR model are nonstationary by the Augmented Dickey Fuller (ADF) and Phillips-Perron (PP) unit root tests as well as a KPSS test of stationarity, as shown in Table 1. Lütkepohl (2005), among others, suggested transforming SVAR variables to stationary for the SVAR to be stationary and stable. Nonstationary variables could result in a nonstationary VAR system and impulse responses that are spurious and do not die down with time.

Stock (1987), West (1988), and Sims et al. (1990) showed that parameter estimates of VAR are consistent when variables are nonstationary, but small samples may result in biased estimates. Sims (1989) suggests that a Bayesian estimation approach may be more appropriate for modeling and estimating VAR models with nonstationary variables. Given the predicted difficulties with the choice of prior distribution for the Bayesian estimation, we opted for estimating VARs with stationary variables.

The stationarity and unit root tests shown in Table 1 confirm our visual observations - that equity indices may be nonstationary. The ADF and PP tests for the unit root and the KPSS test of stationarity show that most variables in every subperiod are nonstationary. In some subperiods, the indices may be marginally stationary. Additionally, the ARCH effects are observed for some indices and in various subperiods.

To ensure that we obtain appropriate measures of volatility and avoid problems stemming from the nonstationarity of the index series, we introduce and estimate a GARCH $(1,1)$ model for the stationary percentage returns in each equity index in each subperiod. The objective is to extract the time-varying heteroscedasticity (i.e., volatility) in each market and subperiod. We specify and estimate the GARCH model in Equations (5) and (6). The ADF, PP, and KPSS tests of stationarity show that the estimated conditional variances for the entire period of study reported in Table 1, Panel F, are stationary. The conditional variance for the SH is marginally stationary. However, once the break points are included, the ADF unit root test is statistically significant for this index. The stationarity tests for the subperiods are not reported for the purpose of brevity but show that conditional variances in all subperiods are stationary. The stationary index volatilities represent each market in the SVAR models.

To derive the structural shocks from SVARs, unrestricted VARs for each subperiod are estimated with the appropriate lag order. Multiple lag order criteria are employed because there may be conflicting signals by various criteria. For instance, the Schwarz Bayesian criterion (SBC) tends to underestimate the number of lags. Too few lags could result in a nonstationary VAR system and residuals that are not white noise. Other lag order criteria, such as the Hannon-Quinn criterion (HQ), the Akaike information criterion (AIC), the forecast prediction error (FPE), and the likelihood ratio test (LR), are also examined.

The VAR lag orders for all subperiods are determined by the FPE, AIC, SC, and HQ. The inverse roots of the characteristic polynomial are all inside of the unit circle, confirming that the estimated VAR systems are stationary in the subperiods. This ensures that the impulse responses eventually die down. Imposing a long-run restriction that matrix $\mathbf{A}^{-1}$ is lower triangular, and we are able to derive the structural innovations vector $\mathbf{u}$ and the impulse responses. The impulse response function is the time path of the volatility in the four equity markets following a positive shock to the OVX index. The impulse responses show the size of the impact of a shock as well as the rate at which the response tapers off. The point estimates and their two-standard-error bands are shown by the solid and dotted lines in all cases.

Figures 2 through 10 show the impulse responses of the four equity volatilities to the OVX shocks. The responses of the volatilities are derived from the moving average representation of the structural model. They show that equity index volatilities do not necessarily respond consistently to OVX shocks. Only in the second and third subperiods do all four equity indices fall in response to positive shocks in the OVX. The impulse responses become statistically insignificant between six and sixteen days. In the interest of 
brevity, we discuss only the impulse responses in the first, second, and third subperiods presented in Figures 2, 4, 6, and 8 .

In subperiod one, the Shanghai and Hong Kong indices react to the OVX as shown by statistically significant impulse responses for several days. The Hong Kong equity index drops and takes around four days to recover from the shocks to the OVX. This is plausible given that the Hong Kong economy is completely dependent on resources imported from abroad, including crude oil. The Shanghai equity index benefits from positive shocks to the OVX. China is the fourth ranking crude oil producer in the world. It became a crude oil importer in 1993. It is conceivable that positive effects of positive shocks to the OVX more than offset the negative consequences of the shocks. This could occur if the crude oil producing sector benefits from rising profits and share prices in this sector. The equity indices of Seoul and Taiwan do not show a statistically significant response to the OVX shocks. In both cases, the two-standarddeviation confidence band includes zero, indicating that the impulse responses are not significantly different from zero. Therefore, the OVX shocks are considered transitory by investors in these two markets. The cumulative responses shown in Figures 3, 5, 7, and 9 in all four markets reflect these findings.

The impulse responses to OVX shocks in the second subperiod by all markets are initially negative and statistically significant. While impulse responses in all markets - except for the Shanghai marketreverse course within eight days, the cumulative responses remain in the negative region, except for the Shanghai market. Once again, the findings indicate that the equity markets for the crude oil-dependent economies are sensitive to OVX shocks and respond negatively. The economy of China appears to benefit from positive shocks to crude oil markets, perhaps because the crude oil-producing sector of the economy benefits from the positive shocks to the OVX. If the remaining sectors pass the higher crude oil costs to the final product prices, then this finding is plausible.

The cumulative impulse response confirms that OVX shocks have a cumulative deleterious effect on three out of four of the equity markets considered in this study. The exception may be the Shanghai equity market, which deviates from this pattern. The volatility in the Shanghai market does not demonstrate a plunge on a cumulative basis. This may indicate that China's oil industry may be acting as a cushion against decline in other sectors.

Only in the third subperiod, which covers January 2018 through November 2018, do all equity markets react negatively to OVX shocks. All indices decline, as shown by Figure 7. The two-standard-deviation confidence interval indicates that impulse responses become statistically insignificant around five days for Korea and Taiwan and roughly thirteen to fourteen days in Hong Kong and Shanghai, respectively. It is evident that heightened OVX may lead to investor anxiety in all equity markets under consideration. Therefore, we can conclude that rising fear reflected by positive shocks to the OVX results in investor anxiety in the four equity indices. The conclusion is that OVX shocks do trigger investor fear and downward market volatility in the third subperiod under consideration. Cumulative impulse responses bolster the aforementioned observation. The positive shocks to the OVX result in a cumulative declining response in all equity markets beyond sixteen days, with the exception of Hong Kong, which takes close to a month to respond.

The third subperiod was dominated by several events that might have directly impacted the Pacific Rim markets. The ongoing trade disagreements between the US and China and the resulting tariffs from both sides threatened world economic stability and shaved off at least one percentage point from the US GDP growth rate. It substantially slowed down the growth rate of the Chinese economy as well. The lack of progress in negotiations between the US and North Korea cast a pall on the security of the region for many years to come. The weight of these negative news events undoubtedly fueled fear and uncertainty in the investing community in the area. Under these conditions of heightened investor nervousness, it is plausible that the markets are more susceptible to negative news. Research has shown that the impact of news on decision makers may depend on the saliency of issues on peoples' minds (see Edwards et al., 1995). It is conceivable that investors in these areas were highly attuned to the information impacting their region and responded to risks introduced by crude oil prices and OVX fluctuations. The accumulated 
impulse responses in the four equity markets to the shocks to the OVX are presented in Figure 8. It is evident that there is a considerable accumulated volatility in response to the shocks to the OVX Index.

The remaining subperiod does not show concrete support for the association between the OVX and the equity indices of East Asia.

Table 2 presents the decomposition of the forecast error of the volatility explained by the SVAR variables in the four subperiods in panels A through D. In the first subperiod, the role of the OVX is minimal in explaining the forecast error variations in all four equity markets. For instance, in all markets, the factors specific to each market and its equities play the most significant role in accounting for the one-day-ahead forecast error variations in that market. However, Shanghai equity market fluctuations also carry significant weight in explaining the forecast error variations in the remaining markets. Considering that China is the second largest economy of the world - it is relatively energy rich and it is possibly second to Japan as the most dominant economy in that region - this finding is not surprising, which may indicate co-movement among these markets.

As Panel B of Table 2 shows, in subperiod two, OVX explains 27-76\% of the one-day-ahead forecast error variations of $\mathrm{HS}, \mathrm{KO}$, and $\mathrm{TW}$ - all indices that represent economies that heavily depend on crude oil imports. However, the Shanghai equity index forecast error variations are not explained by the OVX in any notable manner. The forecast error variations in the Shanghai equity market are mainly explained by events specific to the economy and equity market of China.

According to Table 2, Panel C, $45.45 \%$ of the one-day-ahead forecast error variations of volatility in the HS is because of the shocks to the OVX. The portion of the forecast error in the HS, explained by the OVX, remains above $40 \%$ for forecast errors of six, twelve, eighteen, and twenty-four days in the HS. Similarly, the percentage of the variance of forecast error in the remaining three equity indices are consistently above $30 \%$. The weight of the OVX in accounting for forecast error variations in the four equity indices may show the sensitivity of these equities in response to the CBOE OVX. In summary, the volatility in major emerging equity markets of Asia shows significant response to the OVX. In twentyfour days, the variations in $\mathrm{HS}, \mathrm{KO}, \mathrm{SH}$, and TW-because of the OVX-range from 30-42\%. One concludes that, in this subperiod, the Asian emerging equity markets are sensitive to the US crude oil fear index.

Subperiod three covered almost the entire 2018 calendar year. During this subperiod, many significant events might have contributed to economic uncertainty. This is the year that the Trump administration, following some tariff chatter during 2017, imposed unprecedented punitive tariffs on steel, aluminum, and solar panels from all sources as well as 250 billion dollars of imports from China. The tariffs triggered retaliatory counter tariffs on US exports, widening the trade deficit and igniting a global trade war. Additionally, it triggered a slowdown of economic growth in China. Furthermore, hope for an orderly Brexit was dashed, further fueling market uncertainty. The denuclearization negotiations between the US and North Korea also stalled. The confluence of these events, in addition to other minor geopolitical uncertainties, undoubtedly spilled into the crude oil market. It is plausible that the equity markets under study responded to these uncertainties through the OVX as the catalyst.

In the fourth subperiod, the role of the OVX is minimal in explaining the forecast error variations in all four equity markets. For instance, in all markets, factors specific to each market and its equities play the most significant role in accounting for the forecast error in that market. The significant events of the third subperiod continue to keep markets around the globe in a state of uncertainty. However, the Hong Kong equity market fluctuations also carry a significant weight in explaining the forecast error variations in other areas. It is plausible that the position of Hong Kong as a financial center among the four economies is playing a role in this subperiod. During this period, Hong Kong financial markets may reflect financial uncertainties. Geopolitical uncertainties may have led to financial uncertainties in world financial centers like Hong Kong. The co-movements of other equity markets in the study with the Hong Kong equity index may be a symptom of financial uncertainties.

The impulse responses of the SVAR in at least two subperiods suggest that equity market volatility on the downside rises in response to OVX shocks. Table 1 shows that the equity market indices under study and the OVX are nonstationary in most subperiods. Furthermore, the Johansen-Juselius test of cointegration 
reveals that the five series are in long-run equilibrium with one cointegrating vector. To explore the relationship between the indices in the study and the OVX, we further examined the impulse responses from a VECM. The VECM impulse responses for the entire period of study are presented in Figure 10, which shows that all equity indices decline in response to OVX shocks for the first two days before recovering. These results offer some support for the findings of the SVAR model. To further substantiate our findings, we completed the statistical investigation with Granger causality tests.

\section{Nonlinear Causality Test Results}

We have established that the shocks to the OVX trigger volatility in all equity markets in the second and third subperiods. The responses to the OVX in all markets vary across subperiods and may be influenced by the current events of a specific subperiod. Therefore, it may be informative to examine whether the relationship dynamics may be confirmed by testing for causality. However, a complex nonlinearity in the series may also be present when ARCH effects are found. Therefore, following Adrangi et al. (2015), we applied a nonlinear extension to the standard Granger causality tests (Granger, 1969; Geweke, 1984), which is based on smooth transition regression (STR). The nonlinear impact of $\mathrm{x}$ on $\mathrm{y}$ is characterized by an additive smooth transition component. The following additive smooth transition regression model is specified:

$y_{t}=\pi_{10}+\pi_{1}^{\prime} w_{1}+\left(\pi_{20}+\pi_{2} w_{t}\right) F\left(y_{t-d}\right)+\delta_{1}^{\prime} v_{t}+\left(\delta_{20}+\delta_{2}^{\prime} u_{1}\right) G\left(x_{t-e}\right)+u_{t}$

where $\delta \mathrm{j}=(\delta \mathrm{j} 1 \ldots \delta \mathrm{jq})^{\prime}, \mathrm{j}=1,2, v \mathrm{t}=(\mathrm{xt}-1 \ldots \mathrm{xt}-\mathrm{q})^{\prime}$, and $\mathrm{G}($.$) is a transition function. Noncausality is$ tested as $\mathrm{H0}: \mathrm{G} \equiv 0$ and $\delta 1 \mathrm{i}=0, i=1 \ldots . . q$. The approximation to the aforementioned equation is:

$y_{t}=\bar{\pi}_{10}+\bar{\pi}_{1}^{\prime} w_{1}+\left(\pi_{20}+\pi_{2} w_{t}\right) F\left(y_{t-d}\right)+k^{\prime} v_{t}+\sum_{i=1}^{q} \sum_{j=1}^{q} \varphi_{i j} x_{t-1} x_{t-j}+\sum_{i=1}^{q} \psi_{i} x_{t-1}^{3}+u_{t}$,

where $\mathrm{K}^{\prime}=(\mathrm{k} 1 \ldots . \mathrm{kq})$, and noncausality is supported by $\mathrm{k}_{\mathrm{i}}=0, \varphi_{\mathrm{ij}}=0$ and $\psi_{\mathrm{i}}=0 \mathrm{i}=1 \ldots \mathrm{q}$, and $\mathrm{j}=1 \ldots \mathrm{q}$. Under $\mathrm{H} 0$ the resulting test statistic has an asymptotic $\chi^{2}$ distribution with $\left(\mathrm{q}^{*}(\mathrm{q}+1) / 2\right)+2 \mathrm{q}$ degrees of freedom.

Table 3 presents the results of the nonlinear Granger causality tests for $q=5 \ldots .10$ for four subperiods in panels A through $\mathrm{D}$. We report the $\mathrm{P}$ values for the $\mathrm{F}$ statistics that test the joint null hypotheses of no causality (i.e., that $\mathrm{k}_{\mathrm{i}}=0, \varphi_{\mathrm{ij}}=0$, and $\psi_{\mathrm{i}}=0$ ). Therefore, for some lag levels of variable $\mathrm{x}$, the null may not be rejected. Skalin and Svirta (1999) vary the lag order to detect the possible causality between variables at varying lags.

For the four exchanges and all lag levels - in the second and third subperiods-several P-values for F statistics are less than $10 \%$, showing that the null hypothesis of no causality can only be rejected at $5 \%$ and $10 \%$. Overall, the findings from the nonlinear causality tests support the impulse response and variance decomposition analyses in two subperiods, 2 and 3 only. It may be argued that, for these subperiods, the equity investors in the four economies were more attuned to the geopolitical and economic events - but not during other subperiods. The second and third subperiods were dominated by the ongoing trade disagreements between the US and China. The tariffs imposed by both sides on traded goods in both directions threatened world economic stability and shaved off at least one percentage point from the US GDP growth rate while also slowing down economic growth in China and the rest of the world. The lack of progress in negotiations between the US and North Korea probably weighed heavily on Pacific Rim equity markets. One note of caution is that causality may be considered a higher bar than 
impulse responses to OVX shocks. Therefore, while impulse responses may be significant, causality may fail to show up.

\section{Summary and Conclusions}

The objective of this study was to explore the reaction of four major emerging equity markets of the Pacific Rim to the US oil fear index, OVX. The economies of South Korea, Taiwan, and Hong Kong depend heavily on crude oil imports. While China is the fourth largest crude oil producer in the world, it also depends on imports of this vital energy source. This investigation is timely because the OVX has not attracted the same attention as the US equity market fear index or VIX. The findings of the study should shed some light on the equity market volatility in these economies and offer strategies to international fund managers and central banks in these countries.

It is well known that crude oil prices are prone to volatility stemming from global uncertainties and geopolitical events. While practitioners and academicians have been interested in the role of the VIX as a leading indicator of the volatility in equity markets, the OVX has been the subject of fewer inquiries.

Our study examines the daily data for the period of 2014 through 2019. COVID-19 data are not included because the shock from COVID-19 is expected to be transitory. We find three significant breaks in the OVX series during this period based on the Bai and Perron (2003) test. The breaks in data occur during significant economic and political upheavals, such as Brexit, the US exit from the TPP, the North Korean missile crisis, and the US-China trade dispute and tariffs.

We propose and estimate a SVAR formulation in each subperiod that includes the OVX and volatility in the equity indices under consideration. The time-varying volatility in equity indices are derived from a GARCH $(1,1)$ model of indices for HK HS, China (Shanghai Equity Index), South Korea (Seoul Equity Index), and Taiwan (Taiwan Stock Exchange Index).

The impulse responses from the SVAR estimation show that in the second and third subperiods, from December 2016 through November 2018, volatility in the four markets reacted negatively to positive structural shocks to the OVX. Nonlinear Granger causality tests support these findings. This time period is characterized by significant geopolitical crises: nuclear proliferation on the Korean Peninsula, US unilateral withdrawal from the TPP, US-China trade disputes and tariff threats, and lingering complications surrounding the Brexit referendum. It is plausible that global uncertainties might have heightened sensitivity of the market participants to OVX movements. Granger causality tests lend support to these findings. However, in the remaining two subperiods (i.e., January 2014 to November 2016 and December 2018 to September 2019) we did not find a consistent volatility reaction to OVX shocks. For instance, in subperiod four, the equity markets show a cumulative positive and statistically significant response to shocks to the OVX. This could occur as markets are caught in momentum moves and ignore fundamentals because investor psychology may dismiss these concerns.

Our results support the observations of practitioners regarding the OVX as a leading indicator in the crude oil market. Similar to many other leading indicators, while the OVX may perform as a reliable leading indicator of crude oil market volatility during some periods, this connection may be unstable. Findings from the variance decomposition analysis corroborate impulse responses in the subperiods. For instance, in subperiods two and three, OVX variations appear to explain a significant portion of the one-periodahead forecast errors in all equity indices, perhaps with the exception of the Shanghai equity index.

Market reaction to OVX shocks may depend on the saliency of issues dominating the sentiments of market participants. For instance, in the post-US-China trade tiff, market participants might have expected negative chatter, and markets may have capitalized this negative information. Under these conditions, shocks to OVX played a less significant role in the minds of the participants.

Policy makers and fund managers may consider OVX as one indicator of future equity market fluctuations. Based on the findings of this paper, at high readings of OVX, particularly during the periods of heightened geopolitical upheaval, the oil-importing Pacific Rim economies are vulnerable to crude oil market uncertainties. The governments and policy makers in these economies would be well-advised to collaborate and create strategic oil reserves similar to that in the US and other countries. Financial 
managers, energy dependent firms, and investors in the equities of the Pacific Rim countries may engage in the derivatives markets to hedge their long and short positions in these markets based on the OVX signals. For instance, given that the Pacific Rim economies, with the exception of Hong Kong, are heavily reliant on the export of manufactured goods, purchase of crude oil futures contracts would be prudent. To compensate for possible financial exposure upon delivery of the underlying crude oil due to unpredictable price fluctuations, put options would be advisable. While particular strategies may be beyond the scope of this paper, the most important contribution of the findings of this paper is that upward OVX signals-during periods of significant geopolitical events - should be considered a harbinger of near-term equity market losses.

\section{References}

Adrangi, B., Baade, H., \& Raffiee, K. (2019). Dynamic Responses of the Economy to Monetary Shocks in the United Kingdom. Review of Economics \& Finance, 15, 31-45.

Adrangi, B., Chatrath, A., Macri, J., \& Raffiee, K. (2015). Crude oil price volatility spillovers into major equity markets. Journal of energy markets, 8(1), 77-95.

Adrangi, B., Chatrath, A., Macri, J., \& Raffiee, K. (2018). U.S. Diesel Fuel Price Responses to the Global Crude Oil Supply and Demand, Annals of Financial Economics, pp. 181-825.

Adrangi, B., Chatrath, A., Macri, J., \& Raffiee, K. (2019). Dynamic Responses of Major Equity Markets to the US Fear Index. Journal of Risk and Financial Management, 12(4), 156.

Adrangi, B., Chatrath, A., Macri, J., \& Raffiee, K. (2020). Dynamics of crude oil price shocks and major Latin American Equity Markets: A study in time and frequency domains. Bulletin of Economic Research.

Adrangi, B., Chatrath, A., Raffiee, K., \& Ripple, R. D. (2001). Alaska North Slope crude oil price and the behavior of diesel prices in California. Energy Economics, 23(1), 29-42.

Ahmad, W., Sadorsky, P., \& Sharma, A. (2018). Optimal hedge ratios for clean energy equities. Economic Modelling, 72, 278-295.

Akaike, H. (1974). A new look at the statistical model identification. In Selected Papers of Hirotugu Akaike (pp. 215-222). Springer, New York, NY.

Ang, A., Hodrick, R. J., Xing, Y., \& Zhang, X. (2006). The cross-section of volatility and expected returns. The Journal of Finance, 61(1), 259-299.

Badshah, I. U., Frijns, B., \& Tourani-Rad, A. (2013). Contemporaneous spill-over among equity, gold, and exchange rate Implied Volatility Indices. Journal of Futures Markets, 33(6), 555-572.

Bai, J., \& Perron, P. (2003). Computation and analysis of multiple structural change models. Journal of applied econometrics, 18(1), 1-22.

Blanchard, O. J., \& Quah, D. (1989). The dynamic Effects of aggregate Demand and Supply Disturbances. American Economic Review, 79(4) 655-673.

Blanchard, O. J. (1989). A traditional interpretation of macroeconomic fluctuations. The American Economic Review, 1146-1164.

Bloomberg. https://www.bloomberg.com/graphics/recovery-tracker/, March 2021

Boscaljan, B., and J. Clark. 2013. Do large shocks in VIX signal a flight-to-safety in the gold market? Journal of Applied Finance 2:120-31.

Chen, Y., He, K., \& Yu, L. (2015). The information content of OVX for crude oil returns analysis and risk measurement: Evidence from the Kalman filter model. Annals of Data Science, 2(4), 471-487. 
Cheuathonghua, M., Padungsaksawasdi, C., Boonchoo, P., \& Tongurai, J. (2019). Extreme spillovers of VIX fear index to international equity markets. Financial Markets and Portfolio Management, 33(1), $1-38$.

Edwards III, G. C., Mitchell, W., \& Welch, R. (1995). Explaining presidential approval: The significance of issue salience. American Journal of Political Science, 108-134.

Forbes, What Is The Outlook For Construction Post Pandemic? Apr 20, 2021

Frijns, B., Tallau, C., \& Tourani-Rad, A. (2010). The information content of implied volatility: evidence from Australia. Journal of Futures Markets: Futures, Options, and Other Derivative Products, 30(2), 134-155.

Geng, J. B., Chen, F. R., Ji, Q., \& Liu, B. Y. (2021). Network connectedness between natural gas markets, uncertainty and stock markets. Energy Economics, 95, 105001.

Geweke, J. (1984), Inference and causality in economic time series models, in Z. Griliches and M. D. Intriligator (eds), Handbook of Econometrics, Vol. 2, North-Holland, Amsterdam, 1101 \pm 1144.

Giot, P. (2005). Relationships between implied volatility indices and stock index returns. Journal of Portfolio Management, 31(3), 92-100.

Granger, C. W. (1969). Investigating causal relations by econometric models and cross-spectral methods. Econometrica: Journal of the Econometric Society, 424-438.

GÜRSOY, S. (2020). Investigation of The Relationship Between VIX Index and BRICS Countries Stock Markets: An Econometric Application. Mehmet Akif Ersoy Üniversitesi Uygulamalı Bilimler Dergisi, 4(2), 397-413.

Ji, Q., Bouri, E., \& Roubaud, D. (2018). Dynamic network of implied volatility transmission among US equities, strategic commodities, and BRICS equities. International Review of Financial Analysis, 57, $1-12$.

Johansen, S., \& Juselius, K. (1990). Maximum likelihood estimation and inference on cointegrationwith applications to the demand for money. Oxford Bulletin of Economics and statistics, 52(2), 169210.

Jubinski, D., and A. F. Lipton. 2013. VIX, gold, silver, and oil: How do commodities react to financial market volatility? Journal of Accounting and Finance 13:70-88.

Kang, S., Hernandez, J. A., Sadorsky, P., \& McIver, R. (2021). Frequency spillovers, connectedness, and the hedging effectiveness of oil and gold for US sector ETFs. Energy Economics, 99, 105278.

Kilian, L., \& Park, C. (2009). The impact of oil price shocks on the US stock market. International Economic Review, 50(4), 1267-1287.

Lin, J. B., \& Tsai, W. (2019). The Relations of Oil Price Change with Fear Gauges in Global Political and Economic Environment. Energies, 12(15), 2982.

Lundberg, C., Skolrud, T., Adrangi, B., \& Chatrath, A. (2021). Oil Price Pass through to Agricultural Commodities. American Journal of Agricultural Economics, 103(2), 721-742.

Lütkepohl, Helmut, New Introduction to Multiple Time Series Analysis, Ed. Springer-Verlag, Berlin, 2005.

MacKinnon, J. G., Haug, A. A., \& Michelis, L. (1999). Numerical distribution functions of likelihood ratio tests for cointegration. Journal of applied Econometrics, 14(5), 563-577.

Moody's. Coronavirus-related disruptions to airline industry affect broad swath of global economy New York, July 16, 2020.

Qadan, M., \& Idilbi-Bayaa, Y. (2020). Risk appetite and oil prices. Energy Economics, 85, 104595. 
Sari, R., Soytas, U., \& Hacihasanoglu, E. (2011). Do global risk perceptions influence world oil prices?. Energy Economics, 33(3), 515-524.

Sharma, G., Kayal, P., \& Pandey, P. (2019). Information linkages among BRICS countries: empirical evidence from implied volatility indices. Journal of Emerging Market Finance, 18(3), 263-289.

Sims, C. A. (1989). Models and their uses. American Journal of Agricultural Economics, 71(2), 489-494.

Sims, C. A., Stock, J. H., \& Watson, M. W. (1990). Inference in linear time series models with some unit roots. Econometrica: Journal of the Econometric Society, 113-144.

Skalin, J. \& Svirta, T. (1999). Another Look at Swedish Business Cycles. Journal of Applied Econometrics, 14(4), 359-378.

Stock, J. H. (1987). Asymptotic properties of least squares estimators of cointegrating vectors. Econometrica: Journal of the Econometric Society, 1035-1056.

Vogelsang, T. J. (1997). Wald-type tests for detecting breaks in the trend function of a dynamic time series. Econometric Theory, 13(6), 818-848.

Wen, F., Xiao, Y., \& Wu, H. (2019). The effects of foreign uncertainty shocks on China's macroeconomy: Empirical evidence from a nonlinear ARDL model. Physica A: Statistical Mechanics and its Applications, 532, 121879.

West, K. D. (1988). Asymptotic normality, when regressors have a unit root. Econometrica: Journal of the Econometric Society, 1397-1417. 


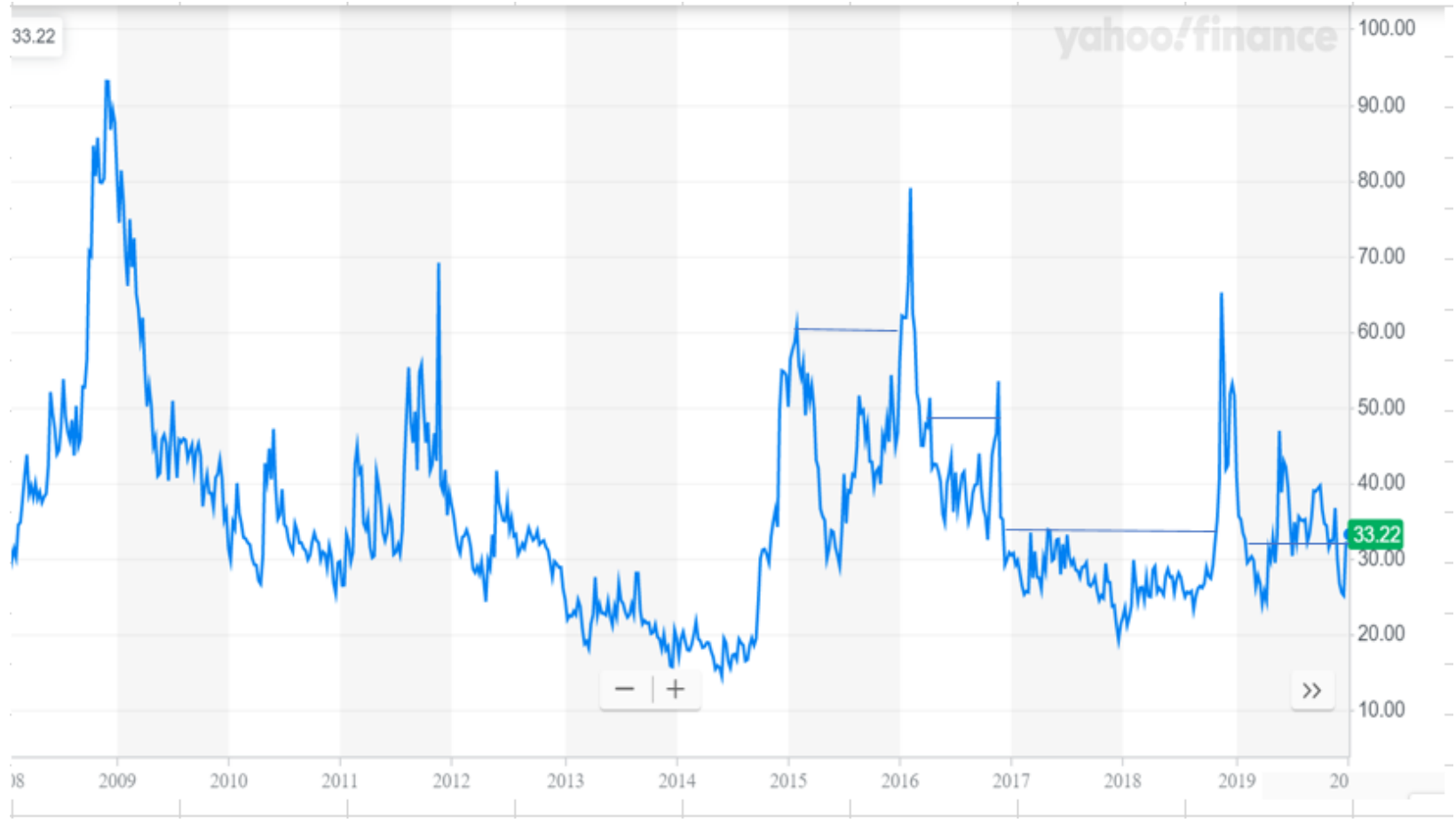

Figure 1: OVX and major breaks. 


\section{Subperiod 1}

Response to Structural VAR Innovations and Two Standard Deviations Confidence Band

Response of Hang Sang volatility to OVX Innovations



Response of Shanghai Index volatility to OVX Innovations

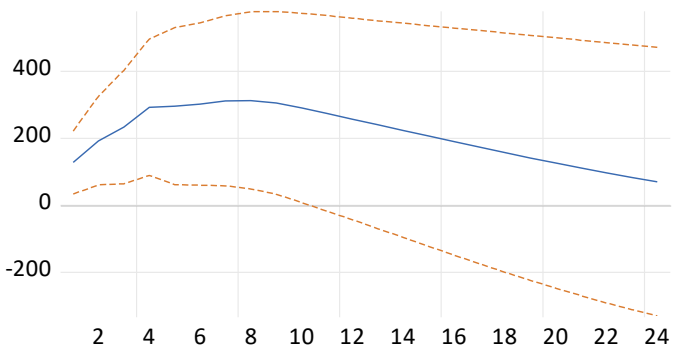

Response of Korea Composite Index volatility to OVX Innovations

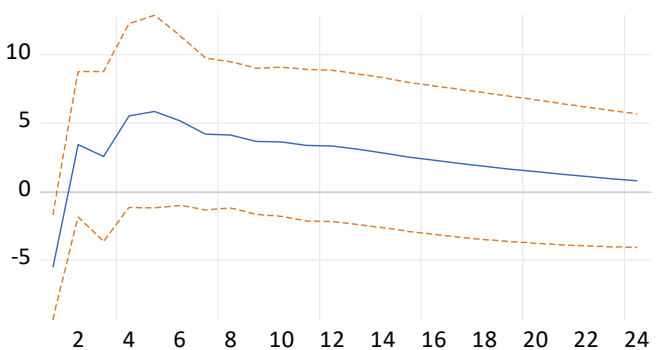

Response of Taiwan Stock Index volatility to OVX Innovations

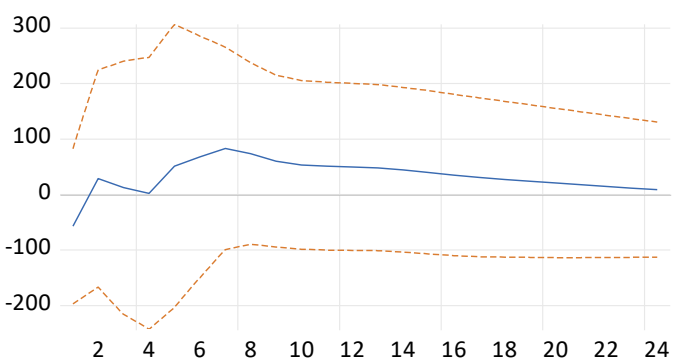

Figure 2: Responses of volatility in Equity Indices to Structural Innovations in OVX. Estimates and TwoStandard Deviation Confidence Band are in solid and dotted lines. SVAR lag order is 5. Long-run identification restrictions are imposed. 9/18/2014-11/30/2016 
Accumulated Response to Structural VAR Innovations and Two Standard Deviations Confidence Band

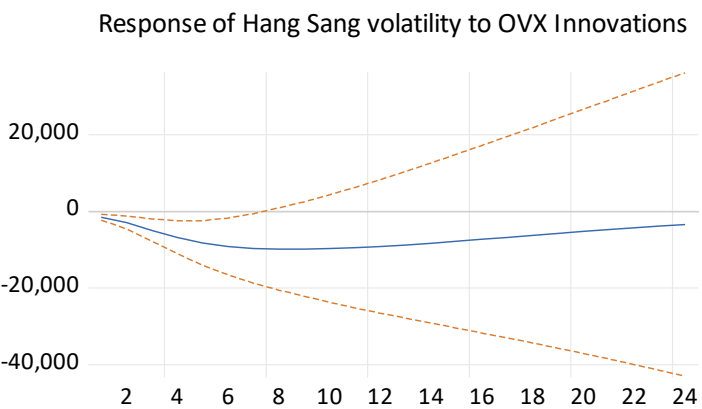

Response of Korea Composite Index volatility to OVX Innovations

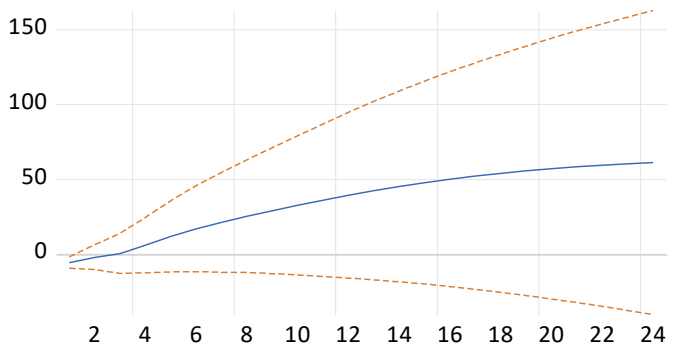

Response of Shanghai Index volatility to OVX Innovations

Response of Taiwan Stock Index volatility to OVX Innovations
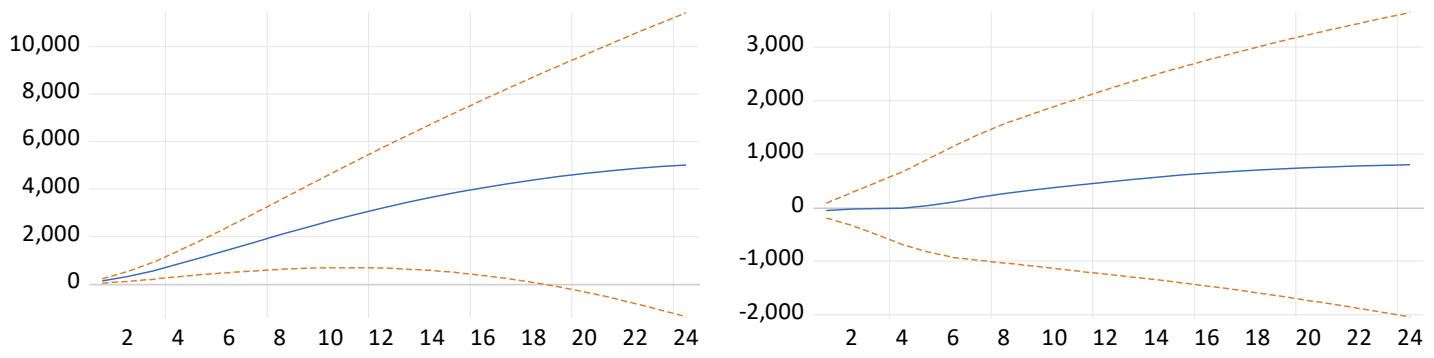

Figure 3: Accumulated responses of volatility in Equity Indices to Structural Innovations in VIX. Estimates and

Two-Standard Deviation Confidence Band are in solid and dotted lines. SVAR lag order is 5. Long-run identification restrictions are imposed. 9/18/2014-11/30/2016. 


\section{Subperiod 2}

Response to Structural VAR Innovations and Two Standard Deviations Confidence Band

Response of Hang Sang volatility to OVX Innovations

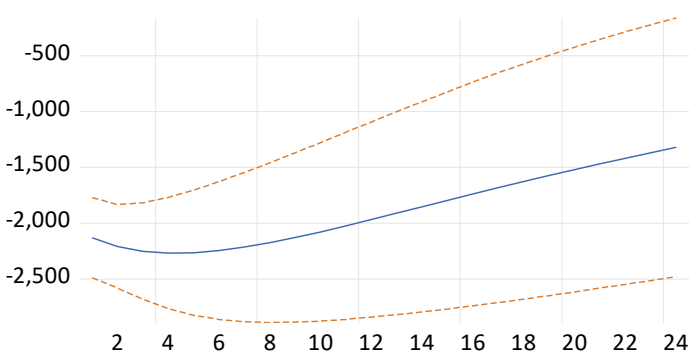

Response of Shanghai Index volatility to OVX Innovations

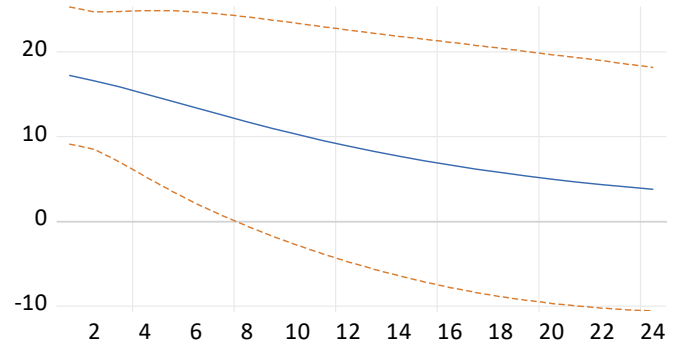

Response of Korea Composite Index volatility to OVX Innovations

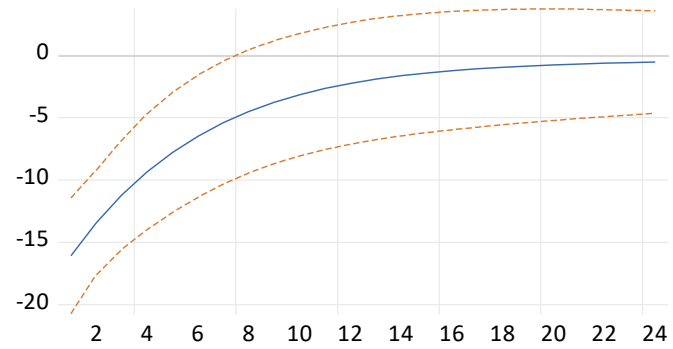

Response of Taiwan Stock Index volatility to OVX Innovations

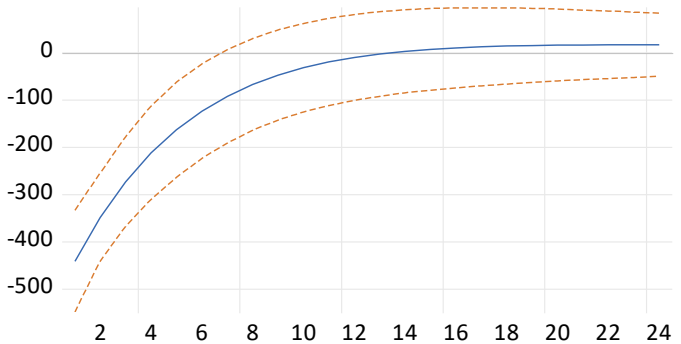

Figure 4: Responses of volatility in Equity Indices to Structural Innovations in VIX. Estimates and Two-Standard Deviation Confidence Band are in solid and dotted lines. SVAR lag order is one. 12/1/2016-12/28/2017. 


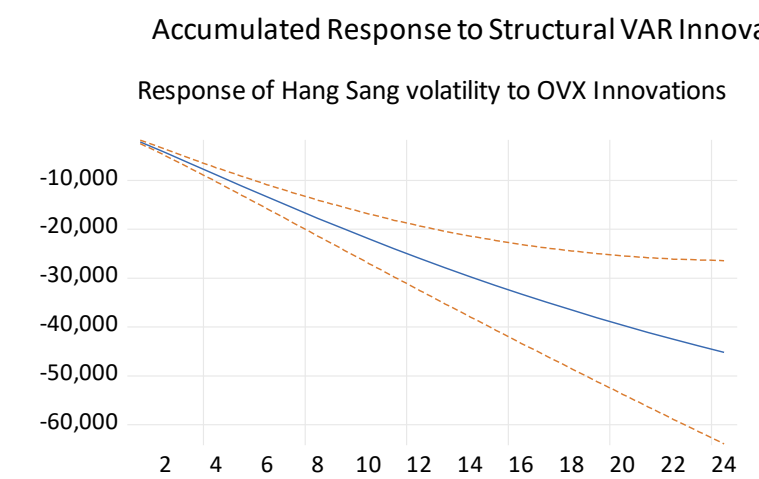

ations and Two Standard Deviations Confidence Band

Response of Korea Composite Index volatility to OVX Innovations

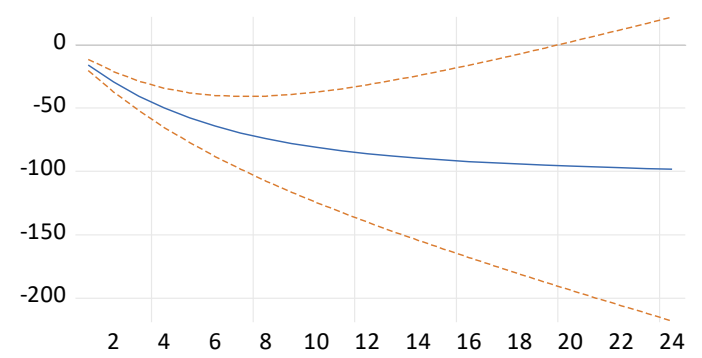

Response of Shanghai Index volatility to OVX Innovations

Response of Taiwan Stock Index volatility to OVX Innovations
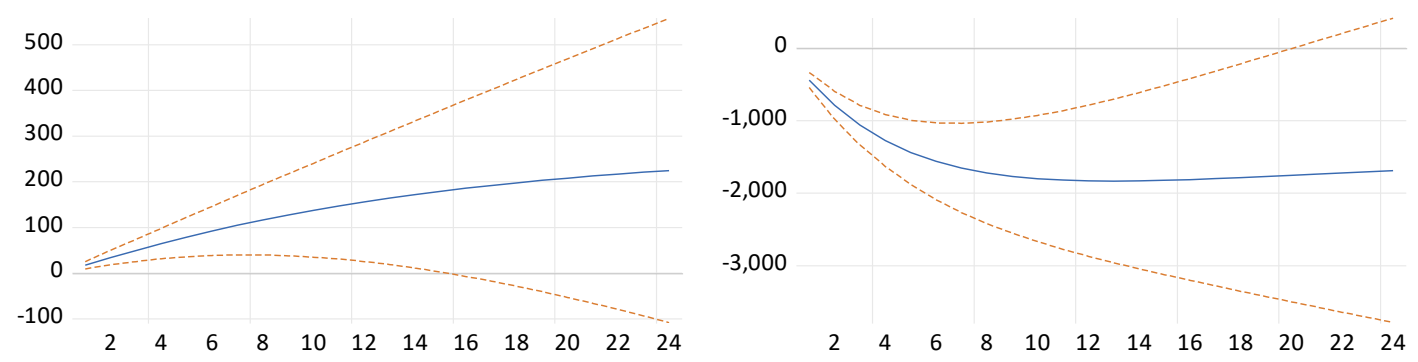

Figure 5: Responses of volatility in Equity Indices to Structural Innovations in VIX. Estimates and Two-Standard Deviation Confidence Band are in solid and dotted lines. SVAR lag order is one. 12/1/2016-12/28/2017. 


\section{Sub-period 3}
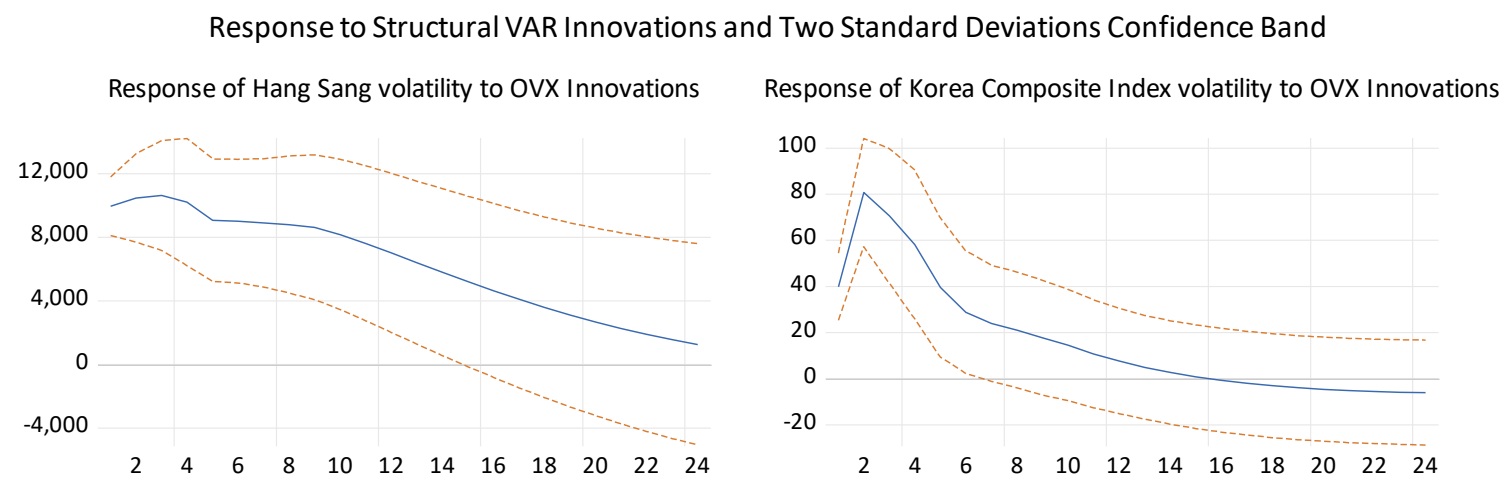

Response of Shanghai Index volatility to OVX Innovations

Response of Taiwan Stock Index volatility to OVX Innovations
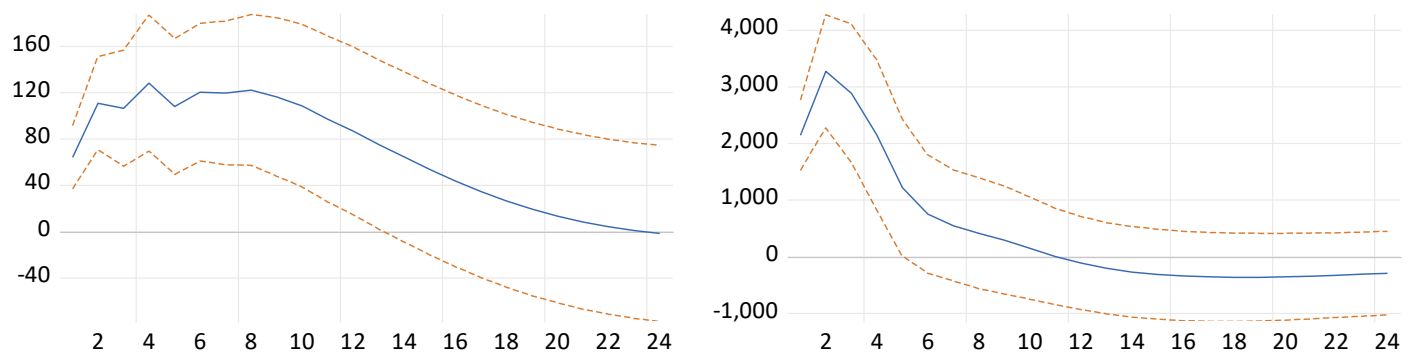

Figure 6: Responses of volatility in Equity Indices to Structural Innovations in VIX. Estimates and Two-Standard Deviation Confidence Band are in solid and dotted lines. SVAR lag order is 4. 1/2/2018- 11/30/2018. 
Accumulated Response to Structural VAR Innovations and Two Standard Deviations Confidence Band

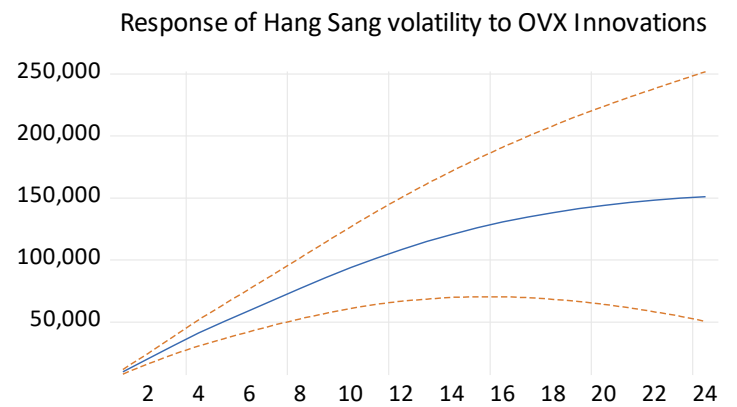

Response of Korea Composite Index volatility to OVX Innovations

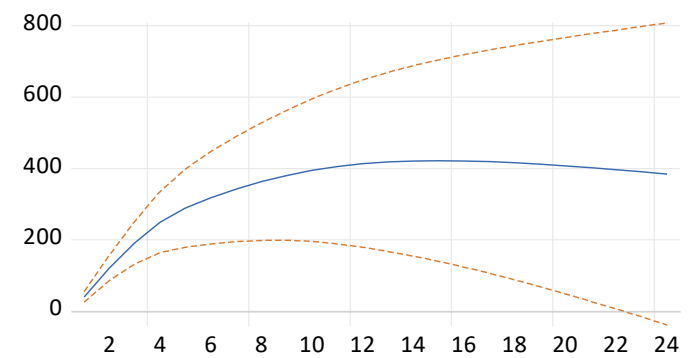

Response of Shanghai Index volatility to OVX Innovations

Response of Taiwan Stock Index volatility to OVX Innovations
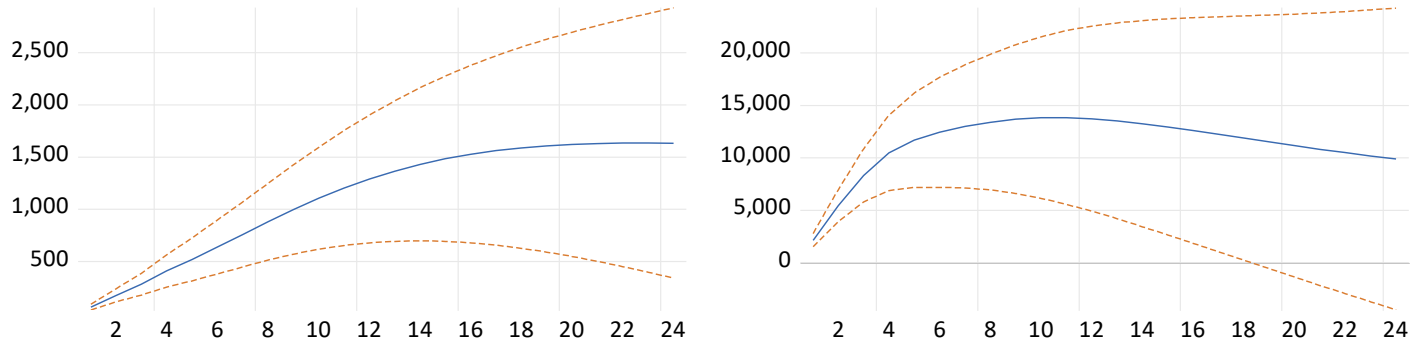

Figure 7: Responses of volatility in Equity Indices to Structural Innovations in OVX. Estimates and TwoStandard Deviation Confidence Band are in solid and dotted lines. SVAR lag order is 4. 1/2/2018- 11/30/2018. 


\section{Sub-period 4}

Response to Structural VAR Innovations and Two Standard Deviations Confidence Band

Response of Hang Sang volatility to OVX Innovations

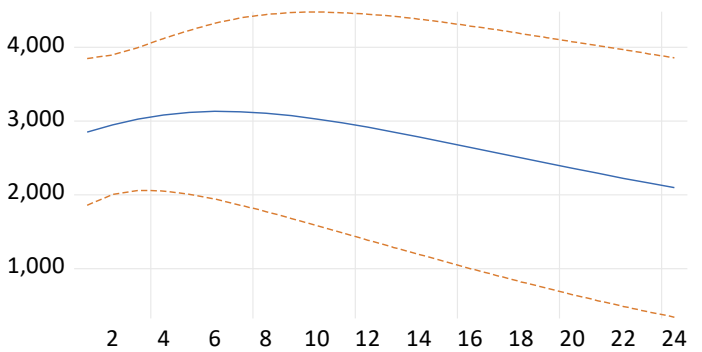

Response of Shanghai Index volatility to OVX Innovations

$$
0
$$

$-40$

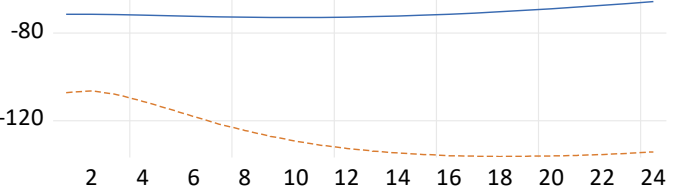

Response of Korea Composite Index volatility to OVX Innovations

12

8

4

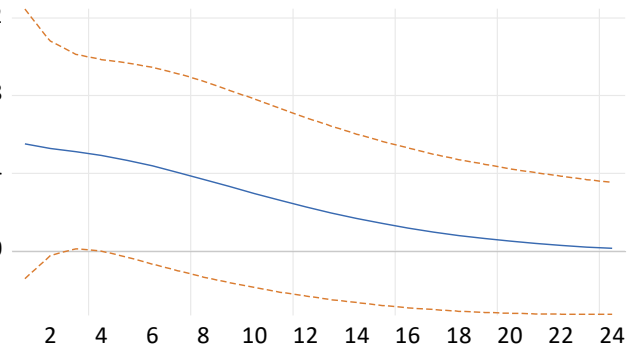

Response of Taiwan Stock Index volatility to OVX Innovations

500

400

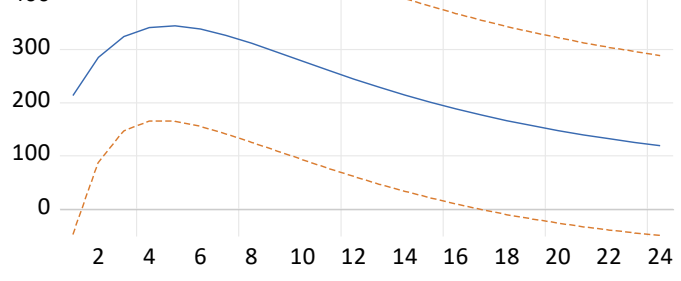

Figure 8: Responses of volatility in Equity Indices to Structural Innovations in OVX. Estimates and TwoStandard Deviation Confidence Band are in solid and dotted lines. SVAR lag order is one. 12/3/2018- 9/27/2019. 
Accumulated Response to Structural VAR Innovations and Two Standard Deviations Confidence Band

Response of Hang Sang volatility to OVX Innovations

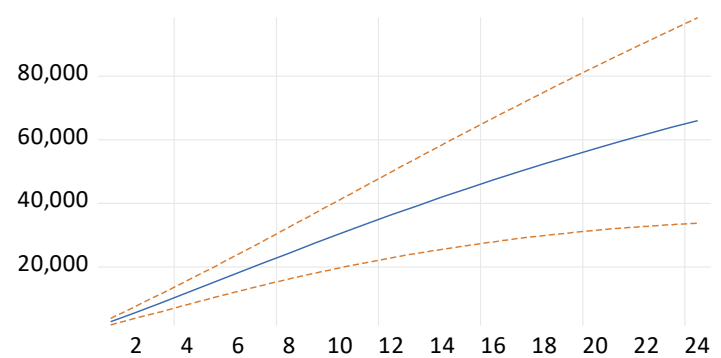

Response of Shanghai Index volatility to OVX Innovations

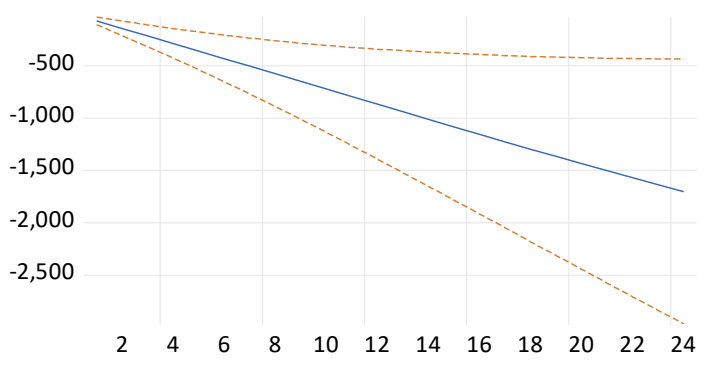

Response of Korea Composite Index volatility to OVX Innovations

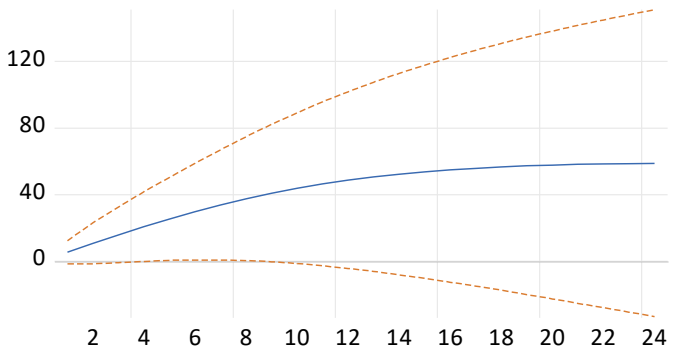

Response of Taiwan Stock Index volatility to OVX Innovations

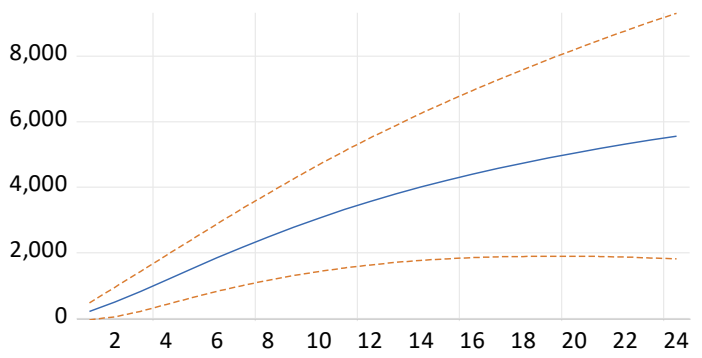

Figure 9: Accumulated responses of volatility in Equity Indices to Structural Innovations in OVX. Estimates and Two-Standard Deviation Confidence Band are in solid and dotted lines. SVAR lag order is one. Long-run identification restrictions are imposed. 6/24/2013-8/12/2015. 
Response to Innovations and Two Standard Deviations Confidence Band
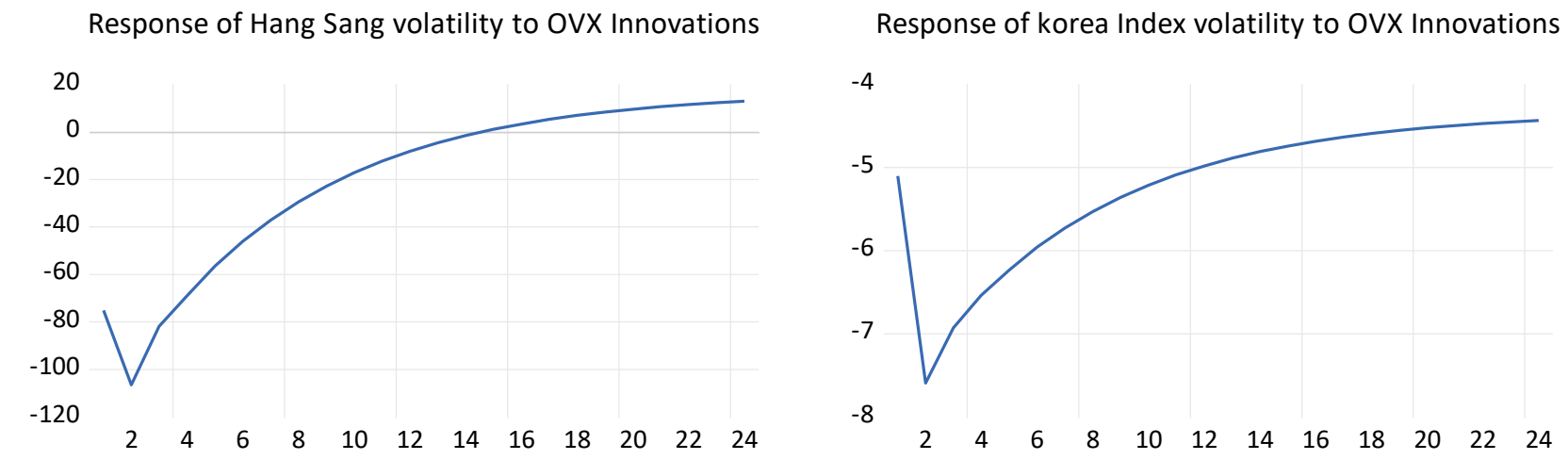

Response of Shanghai Index to OVX Innovations

Response of Taiean Index to OVX Innovation

$-6$

$-7$
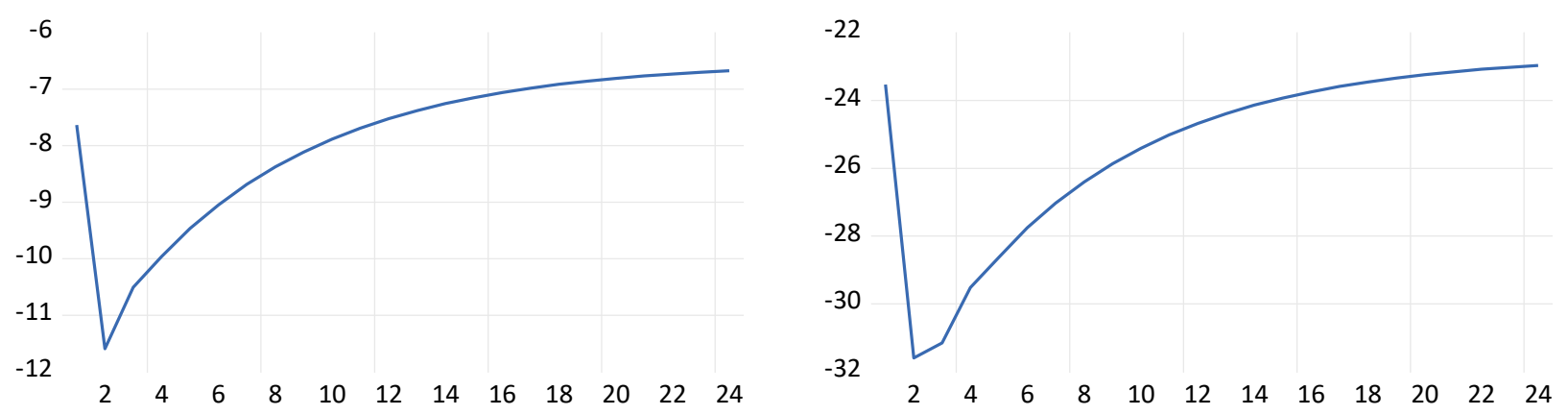

Figure 10: Responses of Equity Indices to Innovations in VIX from Vector Error Correction Model. VECM lag order is one. 9/18/201427/12/2019. 
Table 1: Break Points for OVX, Diagnostics and Summary 9/18/2014-9/29/2019

Panel A: Bai-Perron Test of Structural Breaks

$\begin{array}{lccl}\text { Break Test } & \text { Scaled F-Statistic } & \text { Critical Value } & \text { Dates } \\ 0 \text { vs. } 1^{*} & 17.692 & 11.47 & 9 / 18 / 2014-11 / 30 / 2016 \\ 1 \text { vs. } 2^{*} & 52.759 & & 12 / 1 / 2016-12 / 28 / 2017 \\ 2 \text { vs. } 3^{*} & 12.357 & & 1 / 2 / 2018-11 / 30 / 2018 \\ 3 \text { vs. } 4 & & & 12 / 3 / 2018-9 / 27 / 2019\end{array}$

ADF Unit Root Test with Structural Breaks

Based on the Dickey-Fuller t-statistic, break in trend

Based on the Dickey-Fuller t-statistic, break in intercept and trend

* Bai-Perron (Econometric Journal, 2003) critical values.

${ }^{\mathrm{b}}$ significant at $10 \%$ level, Vogelsang(1997) asymptotic test

Panel B: Levels 9/18/2014-11/30/2016

$\begin{array}{lllll}\text { HS } & \text { KO } & \text { SH } & \text { TW } & \text { OVX }\end{array}$

$\begin{array}{lccccc}\text { ADF } & -1.509 & -3.049^{\mathrm{b}} & -1.915 & -1.793 & -3.361^{\mathrm{b}} \\ \text { PP } & -1.517 & -3.047^{\mathrm{b}} & -2.024 & -1.849 & -3.231^{\mathrm{b}} \\ \text { KPSS } & 1.163 & 0.167^{\mathrm{a}} & 0.451^{\mathrm{b}} & 0.685 & 0.167^{\mathrm{a}} \\ \text { ARCH-LM } & 8.560^{\mathrm{a}} & 8.604^{\mathrm{a}} & 22.921^{\mathrm{a}} & 19.502^{\mathrm{a}} & \end{array}$

Panel C: Levels 12/1/2016-12/28/2017

\begin{tabular}{|c|c|c|c|c|c|}
\hline & HS & $\mathrm{KO}$ & $\mathrm{SH}$ & TW & OVX \\
\hline $\mathrm{ADF}$ & 0.054 & -1.506 & -1.423 & -1.469 & $-4.352^{\mathrm{a}}$ \\
\hline PP & 0.033 & -1.506 & -1.330 & -1.486 & $-4.327^{\mathrm{a}}$ \\
\hline KPSS & 1.129 & 1.803 & 1.180 & 1.868 & 1.033 \\
\hline ARCH-LM & 0.619 & $2.8 * 10^{-6}$ & $6 \quad 0.126$ & 0.004 & \\
\hline \multicolumn{6}{|c|}{ Panel D: Levels 12/29/2017-11/30/2018 } \\
\hline & HS & $\mathrm{KO}$ & $\mathrm{SH}$ & TW & OVX \\
\hline $\mathrm{ADF}$ & -1.229 & -0.885 & -1.070 & -1.614 & 0.339 \\
\hline $\mathrm{PP}$ & -1.271 & -0.931 & -1.075 & -1.615 & -1.332 \\
\hline KPSS & 1.605 & 1.523 & 1.687 & 0.850 & 0.735 \\
\hline
\end{tabular}




\begin{tabular}{|c|c|c|c|c|c|}
\hline ARCH-LM & 0.279 & $18.722^{\mathrm{a}}$ & $13.577^{\mathrm{a}}$ & $28.609^{\mathrm{a}}$ & \\
\hline \multicolumn{6}{|c|}{ Panel E: Levels 12/3/2018-9/27/2019 } \\
\hline & $\mathrm{HS}$ & $\mathrm{KO}$ & $\mathrm{SH}$ & TW & OVX \\
\hline $\mathrm{ADF}$ & -1.163 & -1.419 & -1.512 & -1.179 & $-2.569^{\mathrm{c}}$ \\
\hline PP & -1.278 & -1.724 & -1.592 & -1.240 & $-2.562^{\mathrm{c}}$ \\
\hline KPSS & 0.336 & 0.644 & 0.598 & 1.098 & $0.295^{\mathrm{a}}$ \\
\hline ARCH-LM & 0.358 & 0.804 & 0.002 & 0.014 & \\
\hline \multicolumn{6}{|c|}{ Panel F: GARCH conditional variance (volatility) 9/18/2014-9/27/2019 } \\
\hline & HS & $\mathrm{KO}$ & $\mathrm{SH}$ & TW & \\
\hline $\mathrm{ADF}$ & $-3.314^{\mathrm{a}}$ & $-9.292^{\mathrm{a}}$ & -2.359 & $-11.259^{\mathrm{a}}$ & \\
\hline $\mathrm{PP}$ & $-3.672^{a}$ & $-8.169^{a}$ & $-2.632^{c}$ & $-8.716^{a}$ & \\
\hline KPSS & $0.357^{\mathrm{a}}$ & $0.513^{\mathrm{a}}$ & 1.175 & $0.183^{\mathrm{a}}$ & \\
\hline
\end{tabular}

Panel G: Summary descriptive statistics for model variables. All variables are in level.

\begin{tabular}{lrrrrr} 
& \multicolumn{1}{c}{ HS } & \multicolumn{1}{c}{ KO } & \multicolumn{1}{c}{ SH } & OVX \\
\hline Mean & 25523.90 & 2140.669 & 3131.459 & 9732.736 & 36.503 \\
Stand Dev & 3196.250 & 188.166 & 447.553 & 915.846 & 10.375 \\
Skewness & 0.035 & 0.714 & 1.504 & -0.225 & 0.829 \\
Kurtosis & 2.150 & 2.221 & 7.094 & 1.902 & 3.034 \\
J-B & $33.313^{\mathrm{a}}$ & $121.389^{\mathrm{a}}$ & $1183.191^{\mathrm{a}}$ & $64.539^{\mathrm{a}}$ & 126.196
\end{tabular}

Panel G: Johansen-Juselius Cointegration Test, unrestricted VAR lag order $=6$

$\mathrm{r}=$ The number of cointegrating vectors among the four variables

$\begin{array}{ccccr} & \lambda_{\mathrm{m}} & \text { P-Value } & \lambda_{\mathrm{t}} & \text { P-Value } \\ \mathrm{r}=0 & 31.702^{\mathrm{b}} & 0.088 & 63.534 & 0.143 \\ \mathrm{r} \leq 1 & 15.309 & 0.723 & 31.832 & 0.621\end{array}$

Notes: Order of lags in the VAR for cointegration test is 2, determined by the AIC, SBC, FPE, and likelihood ratio test. KPSS tests include an intercept in the test regression. The null hypothesis in that the series is trend-stationary. Significance indicates nonstationary except for KPSS test. Conditional variance for Shanghai exchange is on the border line of being nonstationary. However, the unit root test accounting for break points show an ADF statistic of 5.410, which is statistically significant. Cointegration with unrestricted intercepts and no trends in the cointegrating VARs. P-values from MacKinnon-Haug-Michelis (1999) for both $\lambda_{m}$ and $\lambda_{t}$ reject no or one cointegrating vector. Maximum eigenvalue test suggests possibly 1 cointegrating vectors at $5 \%$ level.

${ }^{\mathrm{a}},{ }^{\mathrm{b}}$, and ${ }^{\mathrm{c}}$, represent significance at $.01, .05$, and .10 , respectively. 
Table 2: Percentage of Equity Index Volatility Forecast Error Variations Explained by OVX and Major Asian Equity Indices.

Panel A: First Sub-Period: 9/18/2014-11/30/2016

\begin{tabular}{|c|c|c|c|c|c|c|}
\hline $\begin{array}{l}\text { HS } \\
\text { Period }\end{array}$ & S.E. & OVX & HS & $\mathrm{KO}$ & $\mathrm{SH}$ & TW \\
\hline $\begin{array}{l}1 \\
6 \\
12 \\
18 \\
24\end{array}$ & $\begin{array}{l}2.321 \\
4.755 \\
6.005 \\
6.746 \\
7.227\end{array}$ & $\begin{array}{l}3.432 \\
3.383 \\
1.865 \\
1.555 \\
1.433\end{array}$ & $\begin{array}{l}15.595 \\
26.067 \\
43.22 \\
53.515 \\
59.909\end{array}$ & $\begin{array}{l}0.036 \\
1.318 \\
3.13 \\
3.364 \\
2.998\end{array}$ & $\begin{array}{l}80.687 \\
68.947 \\
51.572 \\
41.253 \\
35.33\end{array}$ & $\begin{array}{l}0.251 \\
0.285 \\
0.213 \\
0.314 \\
0.33\end{array}$ \\
\hline $\begin{array}{l}\text { KO } \\
\text { Period }\end{array}$ & S.E. & OVX & HS & $\mathrm{KO}$ & $\mathrm{SH}$ & TW \\
\hline $\begin{array}{l}1 \\
6 \\
12 \\
18 \\
24\end{array}$ & $\begin{array}{l}8401.285 \\
20967.89 \\
28675.48 \\
32837.14 \\
35513.49\end{array}$ & $\begin{array}{l}1.749 \\
2.335 \\
2.68 \\
2.89 \\
2.921\end{array}$ & $\begin{array}{l}0.146 \\
2.953 \\
5.118 \\
6.377 \\
7.227\end{array}$ & $\begin{array}{l}49.492 \\
60.898 \\
63.853 \\
63.208 \\
61.974\end{array}$ & $\begin{array}{l}30.446 \\
22.226 \\
18.761 \\
17.56 \\
17.945\end{array}$ & $\begin{array}{l}18.167 \\
11.589 \\
9.588 \\
9.965 \\
9.933\end{array}$ \\
\hline $\begin{array}{l}\mathrm{SH} \\
\text { Period }\end{array}$ & S.E. & OVX & HS & KO & $\mathrm{SH}$ & $\mathrm{TW}$ \\
\hline $\begin{array}{l}1 \\
6 \\
12 \\
18 \\
24\end{array}$ & $\begin{array}{l}41.828 \\
77.617 \\
91.572 \\
95.139 \\
96.275\end{array}$ & $\begin{array}{l}1.536 \\
4.722 \\
5.099 \\
4.476 \\
3.819\end{array}$ & $\begin{array}{l}91.59 \\
87.959 \\
88.565 \\
87.968 \\
86.969\end{array}$ & $\begin{array}{l}5.125 \\
5.53 \\
3.344 \\
2.337 \\
2.044\end{array}$ & $\begin{array}{l}0.564 \\
0.281 \\
2.125 \\
4.597 \\
6.667\end{array}$ & $\begin{array}{l}1.185 \\
1.508 \\
0.868 \\
0.622 \\
0.501\end{array}$ \\
\hline $\begin{array}{l}\text { TW } \\
\text { Period }\end{array}$ & S.E. & OVX & HS & $\mathrm{KO}$ & $\mathrm{SH}$ & TW \\
\hline $\begin{array}{l}1 \\
6 \\
12 \\
18 \\
24\end{array}$ & $\begin{array}{l}1030.475 \\
2806.649 \\
4167.594 \\
5017.715 \\
5597.687\end{array}$ & $\begin{array}{l}0.14 \\
0.151 \\
0.417 \\
0.506 \\
0.515\end{array}$ & $\begin{array}{l}0.325 \\
1.158 \\
3.14 \\
4.803 \\
6.033\end{array}$ & $\begin{array}{l}41.835 \\
58.378 \\
57.729 \\
56.377 \\
55.291\end{array}$ & $\begin{array}{l}29.466 \\
22.331 \\
20.299 \\
20.15 \\
20.342\end{array}$ & $\begin{array}{l}28.234 \\
17.982 \\
18.416 \\
18.163 \\
17.818\end{array}$ \\
\hline
\end{tabular}

Panel B: Second Sub-Period: 12/1/2016-12/28/2017 


\begin{tabular}{|c|c|c|c|c|c|c|}
\hline \multicolumn{2}{|c|}{ Period HKS.E. } & \multirow{2}{*}{$\frac{\text { OVX }}{\overline{59.872}}$} & \multirow{2}{*}{$\frac{\mathrm{HS}}{2 \overline{29.798}}$} & \multirow{2}{*}{$\frac{\mathrm{KO}}{\overline{0 . \overline{2} 87}}$} & \multirow{2}{*}{$\frac{\mathrm{SH}}{9.8}$} & \multirow{2}{*}{$\frac{\mathrm{TW}}{\mathrm{0.242}}$} \\
\hline 1 & 2.324 & & & & & \\
\hline 6 & 2.715 & 69.047 & 23.928 & 0.177 & 6.691 & 0.158 \\
\hline 12 & 2.951 & 73.588 & 20.777 & 0.143 & 5.359 & 0.132 \\
\hline 18 & 3.105 & 75.924 & 19.028 & 0.129 & 4.801 & 0.118 \\
\hline 24 & 1.274 & 45.599 & 37.901 & 0.72 & 15.028 & 0.752 \\
\hline \multicolumn{7}{|l|}{ KO } \\
\hline Period & S.E. & OVX & HS & $\mathrm{KO}$ & $\mathrm{SH}$ & TW \\
\hline 1 & 3153.196 & 18.17 & 19.56 & 62.24 & 0.021 & 0.009 \\
\hline 6 & 7051.293 & 20.2 & 15.764 & 64.013 & 0.011 & 0.012 \\
\hline 12 & 9021.317 & 20.877 & 14.85 & 64.25 & 0.011 & 0.012 \\
\hline 18 & 10094.61 & 21.029 & 14.75 & 64.197 & 0.011 & 0.014 \\
\hline 24 & 10738.14 & 21.077 & 14.735 & 64.163 & 0.011 & 0.014 \\
\hline \multicolumn{7}{|l|}{$\mathrm{SH}$} \\
\hline Period & S.E. & OVX & HS & $\mathrm{KO}$ & $\mathrm{SH}$ & TW \\
\hline 1 & 37.706 & 7.201 & 1.037 & 5.208 & 86.461 & 0.093 \\
\hline 6 & 61.101 & 8.752 & 1.395 & 3.402 & 86.399 & 0.052 \\
\hline 12 & 63.424 & 9.751 & 1.632 & 2.721 & 85.856 & 0.04 \\
\hline 18 & 63.64 & 10.261 & 1.718 & 2.522 & 85.459 & 0.039 \\
\hline 24 & 63.673 & 10.527 & 1.74 & 2.461 & 85.233 & 0.04 \\
\hline $\begin{array}{l}\text { TW } \\
\text { Period }\end{array}$ & S.E. & OVX & HS & $\mathrm{KO}$ & $\mathrm{SH}$ & TW \\
\hline 1 & 64.082 & 24.46 & 30.805 & 1.72 & 3.208 & 39.807 \\
\hline 6 & 127.73 & 27.044 & 24.234 & 1.456 & 2.307 & 44.959 \\
\hline 12 & 147.37 & 26.965 & 23.604 & 1.41 & 2.442 & 45.578 \\
\hline 18 & 153.272 & 26.836 & 23.761 & 1.412 & 2.596 & 45.396 \\
\hline 24 & 155.167 & 26.863 & 23.794 & 1.411 & 2.638 & 45.295 \\
\hline
\end{tabular}

Panel C: Third Sub-Period: 1/2/2018-11/30/2018

\begin{tabular}{lllllll}
\hline \hline $\begin{array}{l}\text { HS } \\
\text { Period }\end{array}$ & S.E. & OVX & HS & KO & SH & TW \\
\hline \hline 1 & 14770.37 & 45.454 & 44.753 & 0.225 & 1.116 & 8.452 \\
6 & 34144.76 & 50.624 & 38.736 & 2.852 & 3.503 & 4.284 \\
12 & 45584.47 & 47.924 & 43.697 & 2.954 & 2.984 & 2.441 \\
18 & 50491.83 & 45.084 & 47.617 & 2.732 & 2.473 & 2.095 \\
24 & 52762.49 & 42.353 & 50.714 & 2.534 & 2.449 & 1.951 \\
KO & & & & & & \\
Period & S.E. & OVX & HS & KO & SH & TW \\
\hline \hline 1 & 106.513 & 14.022 & 4.275 & 69.141 & 0.155 & 12.407 \\
6 & 244.046 & 31.667 & 11.973 & 52.561 & 0.635 & 3.165
\end{tabular}




\begin{tabular}{lllllll}
12 & 257.483 & 31.037 & 14.797 & 50.48 & 0.656 & 3.029 \\
18 & 259.705 & 30.576 & 15.927 & 49.708 & 0.737 & 3.053 \\
24 & 261.172 & 30.477 & 16.463 & 49.215 & 0.821 & 3.024 \\
\hline \hline SH & & & & & & \\
Period & S.E. & OVX & HS & KO & SH & TW \\
\hline \hline 1 & 198.829 & 10.477 & 13.992 & 10.018 & 36.421 & 29.092 \\
6 & 507.697 & 27.367 & 18.28 & 10.747 & 34.778 & 8.828 \\
12 & 668.65 & 31.815 & 20.995 & 14.371 & 27.307 & 5.512 \\
18 & 701.461 & 32.261 & 21.48 & 15.371 & 25.194 & 5.694 \\
24 & 703.968 & 32.163 & 21.578 & 15.345 & 25.097 & 5.816 \\
\hline \hline TW & & & & & & \\
Period & S.E. & OVX & HS & KO & SH & TW \\
\hline \hline 1 & 4634.815 & 21.451 & 34.42 & 31.134 & 9.879 & 3.116 \\
6 & 9799.971 & 31.63 & 23.686 & 36.453 & 4.141 & 4.091 \\
12 & 10038.44 & 30.733 & 23.95 & 35.93 & 4.086 & 5.301 \\
18 & 10094.71 & 30.968 & 23.697 & 35.648 & 4.327 & 5.359 \\
24 & 10142.39 & 31.32 & 23.479 & 35.504 & 4.384 & 5.313 \\
\hline \hline
\end{tabular}

Panel D: Fourth Sub-Period: 12/3/2018-9/27/2019

\begin{tabular}{lllllll}
\hline \hline $\begin{array}{l}\text { HS } \\
\text { Period }\end{array}$ & S.E. & OVX & HS & KO & SH & TW \\
\hline \hline 1 & 6916.501 & 16.999 & 82.006 & 0.057 & 0.031 & 0.906 \\
6 & 14105.56 & 27.665 & 71.736 & 0.08 & 0.238 & 0.281 \\
12 & 17020.5 & 38.131 & 60.894 & 0.162 & 0.597 & 0.217 \\
18 & 18529 & 44.737 & 54.148 & 0.187 & 0.741 & 0.186 \\
24 & 19443.85 & 48.756 & 50.156 & 0.18 & 0.738 & 0.169 \\
\hline \hline KO & & & & & & \\
Period & S.E. & OVX & HS & KO & SH & TW \\
\hline \hline 1 & 46.398 & 1.409 & 27.556 & 59.283 & 9.089 & 2.662 \\
6 & 69.444 & 3.101 & 24.019 & 63.699 & 7.69 & 1.491 \\
12 & 71.795 & 4.097 & 22.85 & 63.983 & 7.541 & 1.53 \\
18 & 72.378 & 4.251 & 22.968 & 63.422 & 7.851 & 1.507 \\
24 & 72.505 & 4.254 & 23.005 & 63.257 & 7.98 & 1.503 \\
\hline \hline SH & & & & & & \\
Period & S.E. & OVX & HS & KO & SH & TW \\
\hline \hline 1 & 242.749 & 8.656 & 12.092 & 9.024 & 70.143 & 0.085 \\
6 & 518.868 & 11.476 & 8.953 & 10.135 & 69.407 & 0.028 \\
12 & 639.694 & 15.316 & 6.97 & 10.353 & 67.342 & 0.019 \\
18 & 699.936 & 19.051 & 5.929 & 10.162 & 64.841 & 0.016 \\
24 & 735.78 & 22.322 & 5.369 & 9.867 & 62.427 & 0.015 \\
\hline \hline
\end{tabular}




\begin{tabular}{lllllll}
$\begin{array}{l}\text { TW } \\
\text { Period }\end{array}$ & S.E. & OVX & HS & KO & SH & TW \\
\hline \hline 1 & 1744.357 & 1.499 & 58.111 & 1.016 & 5.148 & 34.226 \\
6 & 2568.054 & 8.826 & 51.535 & 6.172 & 3.588 & 29.88 \\
12 & 2749.665 & 14.265 & 45.401 & 7.965 & 5.987 & 26.382 \\
18 & 2820.199 & 16.489 & 43.183 & 8.076 & 7.172 & 25.08 \\
24 & 2849.413 & 17.548 & 42.352 & 8.012 & 7.519 & 24.569 \\
\hline \hline
\end{tabular}

Notes: Factorization: Structural 
Table 3: Nonlinear Granger Causality Test: P-Values of F statistics for the Ho of no nonlinear Granger Causality

Panel A: First Sub-Period: 9/18/2014-11/30/2016

\begin{tabular}{|c|c|c|c|c|c|}
\hline \multirow[b]{2}{*}{ Lags } & \multicolumn{2}{|c|}{ Causing Variable } & \multicolumn{2}{|c|}{ Caused Variables } & \multirow[b]{2}{*}{ TW } \\
\hline & OVX & HK & $\mathrm{KO}$ & $\mathrm{SH}$ & \\
\hline 5 & & 0.564 & 0.364 & 0.273 & 0.554 \\
\hline 6 & & 0.260 & 0.538 & 0.453 & 0.413 \\
\hline 7 & & 0.487 & 0.685 & 0.692 & 0.397 \\
\hline 8 & & 0.635 & 0.636 & 0.697 & 0.285 \\
\hline 9 & & 0.819 & 0.309 & 0.802 & 0.235 \\
\hline 10 & & 0.689 & 0.252 & 0.602 & 0.404 \\
\hline
\end{tabular}

Panel B: Second Sub-Period: 12/1/2016-12/28/2017

\begin{tabular}{lllll} 
& HK & KO & SH & TW \\
\hline 5 & 0.677 & 0.608 & 0.047 & 0.692 \\
6 & 0.726 & 0.636 & 0.017 & 0.567 \\
7 & 0.948 & 0.694 & 0.068 & 0.519 \\
8 & 0.920 & 0.623 & 0.034 & 0.533 \\
9 & 0.758 & 0.321 & 0.019 & 0.444 \\
10 & 0.839 & 0.509 & 0.063 & 0.746 \\
\hline
\end{tabular}

Panel C: Third Sub-Period: 1/2/2018-11/30/2018

\begin{tabular}{lcccc}
\hline & HK & KO & SH & TW \\
\hline 5 & 0.075 & 0.008 & 0.264 & 0.088 \\
6 & 0.103 & 0.020 & 0.209 & 0.076 \\
7 & 0.071 & 0.002 & 0.344 & 0.069 \\
8 & 0.036 & 0.008 & 0.154 & 0.126 \\
9 & 0.011 & 0.006 & 0.166 & 0.014 \\
10 & 0.007 & 0.036 & 0.072 & 0.097 \\
\hline
\end{tabular}


Panel D: Fourth Sub-Period: 12/3/2018-9/27/2019

\begin{tabular}{lllll} 
& HK & KO & SH & TW \\
\hline 5 & 0.909 & 0.532 & 0.105 & 0.454 \\
6 & 0.918 & 0.703 & 0.318 & 0.680 \\
7 & 0.729 & 0.520 & 0.632 & 0.219 \\
8 & 0.472 & 0.284 & 0.393 & 0.269 \\
9 & 0.280 & 0.239 & 0.275 & 0.087 \\
10 & 0.341 & 0.204 & 0.464 & 0.126 \\
\hline
\end{tabular}

Notes: The reported P-values are for the $\mathrm{F}$ statistic for of the test for joint null hypotheses of no causality, i.e. that $\mathrm{k}_{\mathrm{i}}=0, \varphi_{\mathrm{ij}}=0$ and $\psi_{\mathrm{i}}=0$. Therefore, at some lag levels of variable $\mathrm{x}$ the null may not be rejected. For instance, the computed P-values for the OVX causing SH for 12/1/2016-12/28/2017 interval show that the former causes the latter for all lags. The degrees of freedom in the numerator and the denominator of the F- test of causality are $q *(\mathrm{q}+$ $1) / 2+2 q$ and $T-n-q^{*}(q+1) / 2-2 q$, respectively, where $q$ is the number of lags, $n$ is the dimension of the gradient vector and $\mathrm{T}$ is the number of observations. Degrees of freedom in the numerator of the $\mathrm{F}$ statistics are 25, 32, 42, 52,63 , and 75 for $\mathrm{q}=5$ through 10 respectively. 